\title{
Potential of IL-1, IL-18 and Inflammasome Inhibition for the Treatment of Inflammatory Skin Diseases
}

\author{
Gabriele Fenini, Emmanuel Contassot* and Lars E. French* \\ Department of Dermatology, University Hospital Zurich, Zurich, Switzerland
}

In 2002, intracellular protein complexes known as the inflammasomes were discovered and were shown to have a crucial role in the sensing of intracellular pathogen- and danger-associated molecular patterns (PAMPs and DAMPs). Activation of the inflammasomes results in the processing and subsequent secretion of the pro-inflammatory cytokines IL-1 $\beta$ and IL-18. Several autoinflammatory disorders such as cryopyrin-associated periodic syndromes and Familial Mediterranean Fever have been associated with mutations of genes encoding inflammasome components.

OPEN ACCESS

Edited by:

Francesca Oliviero,

University of Padua, Italy

Reviewed by:

Pallavi R. Devchand,

Icahn Institute for Genomics and Multiscale Biology at Mount Sinai,

United States

Giuseppe Valacchi,

University of Ferrara, Italy

*Correspondence:

Lars E. French

lars.french@usz.ch

Emmanuel Contassot

emmanuel.contassot@usz.ch

Specialty section:

This article was submitted to Inflammation Pharmacology,

a section of the journal

Frontiers in Pharmacology

Received: 02 February 2017 Accepted: 02 May 2017 Published: 22 May 2017

Citation:

Fenini G, Contassot E and French LE (2017) Potential of IL-1, IL-18 and Inflammasome Inhibition

for the Treatment of Inflammatory Skin

Diseases. Front. Pharmacol. 8:278.

doi: 10.3389/fphar.2017.00278
Moreover, the importance of IL-1 has been reported for an increasing number of autoinflammatory skin diseases including but not limited to deficiency of IL-1 receptor antagonist, mevalonate kinase deficiency and PAPA syndrome. Recent findings have revealed that excessive $\mathrm{IL}-1$ release induced by harmful stimuli likely contributes to the pathogenesis of common dermatological diseases such as acne vulgaris or seborrheic dermatitis. A key pathogenic feature of these diseases is IL-1 $\beta$-induced neutrophil recruitment to the skin. IL-1 $\beta$ blockade may therefore represent a promising therapeutic approach. Several case reports and clinical trials have demonstrated the efficacy of $\mathrm{IL}-1$ inhibition in the treatment of these skin disorders. Next to the recombinant IL-1 receptor antagonist (IL-1Ra) Anakinra and the soluble decoy Rilonacept, the anti-IL-1 $\alpha$

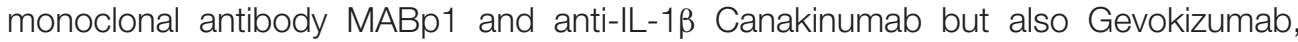
LY2189102 and P2D7KK, offer valid alternatives to target IL-1. Although less thoroughly investigated, an involvement of IL-18 in the development of cutaneous inflammatory disorders is also suspected. The present review describes the role of IL-1 in diseases with skin involvement and gives an overview of the relevant studies discussing the therapeutic potential of modulating the secretion and activity of $\mathrm{LL}-1$ and IL-18 in such diseases.

Keywords: IL-1, IL-1alpha, IL-1beta, IL-18, inflammatory skin conditions, inflammasome

\section{INTERLEUKIN-1 FAMILY}

Cytokines comprise a variety of molecules secreted by immune and non-immune cells that regulate important cellular functions and physiological processes especially in the hematopoietic and immune systems. One important class of cytokines are the interleukins, a large family of small secreted proteins that bind to specific membrane receptors on target cells. The history of 
interleukins, and particularly of interleukin-1 (IL-1), began in 1948 when Paul B. Beeson discovered an active unknown substance obtained from rabbit leukocytes that was able to cause fever (Beeson, 1948). Decades later, Dinarello et al. $(1974,1977)$ identified two chemically and biologically distinct pyrogenic molecules produced by neutrophils and monocytes incubated with heat-killed Staphylococcus albus; he named them human leukocytic pyrogens (LP). Before him, Gery et al. (1972) reported that the stimulation of murine and human lymphocytes with lipopolysaccharide (LPS), an essential component of Gram-negative bacteria, led to the release of a soluble factor that was able to enhance the response of $\mathrm{T}$ lymphocytes to lectins (phytohemagglutinin and concanavalin A). In 1979, the molecules with inflammatory properties reported by Charles Dinarello and Igal Gery revealed to be the same, namely IL-1 (Rosenwasser et al., 1979). Following progress in sequencing technologies, it turns out that the IL-1 family comprises a total of eleven members with similar or distinct biological effects. In addition to IL- $1 \alpha$ and $\beta$, IL-18, IL-33, IL-36 $\alpha, \beta$ and $\gamma$ are pro-inflammatory, whilst, IL-1 receptor agonist (IL-1Ra), IL-36Ra, IL-37, and IL-38 are anti-inflammatory. Genes encoding IL-1 family members are mostly located on human chromosome 2 with two exceptions, namely the genes encoding IL-18 and IL-33 that are located on chromosomes 11 and 9, respectively.

IL-1 $\beta$ is not only secreted by immune cells such as monocytes/macrophages, dendritic cells, neutrophils, B lymphocytes and NK cells but also by non-immune cells such as keratinocytes (Dinarello, 2009; Feldmeyer et al., 2010). IL-1 $\beta$ is able to act on a broad range of cell types (Dinarello, 2009, 2011). It is a key mediator of the acute phase of inflammation inducing local and systemic responses. Its effects are numerous and include the secretion of downstream pro-inflammatory mediators such as cyclooxygenase type-2 (COX-2), IL-6, Tumor Necrosis Factor (TNF) and IL-1 itself (Dinarello, 1996; Weber et al., 2010). In the body, the inflammatory effects of IL-1 manifest as fever, vasodilation and hypotension as well as an increased sensitivity to pain. The pyrogenic activity of IL-1 is due to the activation of NF- $\mathrm{BB}$ and the resulting expression of COX-2, an enzyme involved in the synthesis of prostaglandins (Lee et al., 2004).

IL-1 cytokines bind to and act through specific receptors, which are characterized by intracellular Toll/Interleukin-1 receptor (TIR) domains and an extracellular immunoglobulin-like binding domain (Boraschi and Tagliabue, 2013). The IL-1 receptor family comprises several members including IL-1R1, the decoy receptor IL-1R2, IL-1R accessory protein (IL-1RaP or IL-1R3), IL-1R4 (T1 or ST2), IL-18R $\alpha$ (IL-1R5), IL-36R (IL-1R6), IL-18R accessory protein (IL-18R $\beta$ or IL-1R7), IL-1R8 (TIR8), IL-1R9 (IL-1RAPL2), and IL-1R10 (TIGIRR).

IL-1 $\alpha /$ IL-1 $\beta$, IL-18, and IL-36 initiate immune and inflammatory responses by binding to IL-1R1, IL-18R $\alpha$, and IL-36R, respectively. The co-receptor IL-1RaP interacts with IL-1R1, IL-1R2, IL-1R4, and IL-36R while IL-18R $\beta$ is a unique accessory chain for IL-18R $\alpha$. The decoy receptor IL-1R2 lacks the cytoplasmic TIR domains and is therefore unable to initiate a signaling cascade even in the presence of its accessory receptor. IL-1R2 binds IL-1 $\beta$ with high affinity and IL- $1 \alpha$ or IL-1Ra with low affinity (Symons et al., 1995). The biological activity of IL-1 family cytokines is tightly regulated not only by decoy receptors but also by soluble receptor antagonists such as IL-1Ra and IL-36Ra that can specifically antagonize IL-1 $\alpha$, IL-1 $\beta$, and IL-36. In addition, IL-1R1 can be released into the extracellular space where, in its soluble form (sIL-1R1), it can also function as a soluble decoy receptor and prevent the binding of IL- $1 \alpha$, IL-1 $\beta$, and IL-1Ra to membrane IL-1R1 (Burger et al., 1995). Furthermore, IL-1R2 can also be cleaved and solubilized by metalloproteinases resulting in an increased segregation of IL-1 $\beta$ due to its higher affinity (Symons et al., 1995).

First identified and described as interferon- $\gamma$-inducing factor (IGIF) (Nakamura et al., 1989, 1993), IL-18 received its current name 3 years later (Ushio et al., 1996). In contrast to the strong pyrogenic activity of IL- $1 \alpha$ and IL- $1 \beta$, IL-18 is only able to induce fever at higher concentrations. IL-18 activates primarily p38 MAPK and AP-1, but fails to activate NF-кB (Lee et al., 2004). IL-18 activity is mainly regulated by a soluble protein called IL-18 binding protein (IL-18BP). IL-18BP differs from the other soluble IL-1 receptors because it retains a unique binding sequence composed by a single immunoglobulin domain (Dinarello et al., 2013). Similar to the IL-1Rs, IL-18Rs can also be found in a soluble form that is used as a biomarker for inflammatory diseases such as rheumatoid arthritis (RA) and adult-onset Still's disease (AoSD) (Takei et al., 2011).

Both IL- $1 \beta$ and IL-18 are first synthesized as precursors which need to be processed into their biologically active form by a cytoplasmic protein complex known as the inflammasome. In contrast, both pro and cleaved forms of IL-1 $\alpha$ are biologically active and induce, via IL-1R1 signaling, the production of TNF $\alpha$ and IL-6 in human A549 epithelial cells and peripheral blood mononuclear cells (PBMCs) (Kim et al., 2013). The transcription of the IL- $1 \alpha$ gene is regulated by a variety of stimuli including proinflammatory or stress-associated stimuli and growth factors (Di Paolo and Shayakhmetov, 2016). Pro-IL-1 $\alpha$ lacks a signal secretion peptide, however, its release from dying cells is able to trigger acute inflammation (Chen et al., 2007). IL-1 $\alpha$ can be translocated to the plasma membrane where it signals in an intra and paracrine manner but can also be secreted in its mature form via both IL-1 $\beta$-dependent or independent pathways (Fettelschoss et al., 2011; Gross et al., 2012). Since pro-IL-1 $\alpha$ contains a nuclear localization signal, it can induce the expression of proinflammatory genes independently of IL-1R1 signaling (Werman et al., 2004). Because of the multiplicity of mechanisms of action of IL- $1 \alpha$, it plays an important role in the maintenance of homeostasis and the pathology of several human diseases (Di Paolo and Shayakhmetov, 2016).

\section{PATHOGEN RECOGNITION RECEPTORS}

Pathogen recognition is fulfilled by a distinct set of receptors, the so-called pathogen-recognition receptors (PRRs). These include C-type lectin receptors (CLRs), Toll-like receptors (TLRs), retinoic acid-inducible gene I (RIG-I)-like receptors (RLRs), nucleotide-binding oligomerization domain (NOD)-like 
receptors (NLRs), AIM2-like receptors (ALRs), and partially the complement system. Such PRRs have different localizations and ligands. For example: the complement system acts as an extracellular sensor for conserved pathogen motives (carbohydrates) and host antibodies; TLRs are found on cellular membrane and endosomes and bind to a variety of molecules including nucleic acids (TLR3, TLR8, TLR9, and TLR13), small proteins (TLR2, TLR4, TLR11, and TLR12), lipopeptides and lipoproteins (TLR1, TLR2, and TLR6), glycolipids (TRL2, TLR4) and small drugs (TLR4, TLR7) (Leifer and Medvedev, 2016). CLRs are either localized at the cell surface or in endosomes and primarily bind to carbohydrates (mannose, fucose, GlcNAc, and $\beta$-1,3-glucan) in a $\mathrm{Ca}^{2+}$-dependent manner but the recognition of proteins, lipids and inorganic compounds like $\mathrm{CaCO}_{3}$ has also been reported (Zelensky and Gready, 2005).

Retinoic acid-inducible gene I (RIG-I)-like receptors and NLRs are exclusively located in the cytosol. RLRs include RIG-I, MDA5 and the co-receptor LGP2. They are specialized in the sensing of viral double-stranded RNA (Reikine et al., 2014). NLRs constitute an expanding family of receptors able to detect a variety of molecules. They are composed of several domains: the central NOD or nucleotide-binding domain (NBD) that includes a NTPase NACHT domain controlling self-oligomerization, and the leucine-rich repeat (LRR) domain involved in ligand sensing (Schroder and Tschopp, 2010). On their N-terminal extremity, NLRs have either a pyrin domain (PYD), a caspase-recruitment domain (CARD) or a baculoviral inhibition of apoptosis protein repeat domain (BIR) and are consequently named NLRPs, NRLCs or NAIPs, respectively.

\section{THE INFLAMMASOMES}

In 2002, the group of Prof. Tschopp described a multiprotein complex able to oligomerize and activate inflammatory caspases leading to the processing of IL-1 $\beta$ and IL-18 (Martinon et al., 2002). This complex was named NLR PYD-containing protein 1 (NLRP1)-inflammasome and was shown to contain the scaffold NLRP1 interacting via PYD with the adaptor protein apoptosisassociated speck-like protein containing a CARD (ASC, also known as PYCARD) which can then recruit the inflammatory procaspase, caspase-1(also known as IL-1 $\beta$-converting enzyme or ICE). Upon sensing of appropriate ligands and subsequent inflammasome activation, procaspase- 1 is autocatalytically cleaved and activated (Wilson et al., 1994). Active caspase-1 can then process IL- $1 \beta$ and IL-18 and the biologically active cytokines are secreted in an unconventional golgi/endoplasmic reticulum-independent manner (Keller et al., 2008). The NLRP1 inflammasome is able to sense bacterial peptidoglycan muramyl dipeptide (MDP) (Hsu et al., 2008) and can be activated in keratinocytes by ultraviolet B (UVB) irradiation (Feldmeyer et al., 2007). Mutations in the Nlrp1 gene have been linked to susceptibility to vitiligo-associated autoimmune diseases (Jin et al., 2007), systemic lupus erythematosus (SLE) and RA (Masters, 2013). Gain-of-function mutations of the NLRP1 gene were recently described in two skin disorders, namely multiple self-healing palmoplantar carcinoma (MSPC) and familial keratosis lichenoides chronica (FKLC). NLRP1 mutations result in the blockade of the autoinhibitory effect of NLRP1 PYD domain and lead to an increased activation of the inflammasome (Zhong et al., 2016). NLRP1 also contains a C-terminal CARD domain which mediates direct interaction with caspase-1. A recent study has demonstrated that anthrax lethal factor can cleave the PYD domain of murine but not human NLRP1 causing its activation. This identifies proteolysis as an alternative activation mechanism for NLRP1 (Chavarria-Smith et al., 2016).

The NLRP3 inflammasome is the best characterized inflammasome to date, and a broad range of stimuli can induce its activation. These include PAMPs such as LPS, fungal zymosan, bacterial toxins, and also the bacteria Listeria monocytogenes (Meixenberger et al., 2010), S. aureus (Munoz-Planillo et al., 2009), and Propionibacterium acnes (Kistowska et al., 2014b; Qin et al., 2014), as well as yeasts like Candida albicans (Hise et al., 2009) and of the Malassezia spp. (Kistowska et al., 2014a). NLRP3 can also be activated by danger-associated molecules that are not derived from pathogens but often associated with cellular stress, the so-called DAMPs, including extracellular ATP (Mariathasan et al., 2006), asbestos (Dostert et al., 2008), amyloid- $\beta$ (Halle et al., 2008), DNA:RNA hybrids (Kailasan Vanaja et al., 2014), and crystals such as gout-causing monosodium urate (MSU) (Martinon et al., 2006), silica (Dostert et al., 2008), or cholesterol (Duewell et al., 2010). Interestingly, the study of patients with autosomal dominant cold-induced urticaria, later termed familial cold autoinflammatory syndrome (FCAS), allowed the identification of mutations in the CIAS1/cryopyrin/NLRP3 gene (Hoffman et al., 2001). These studies permitted major advances in the identification and understanding of autoinflammatory diseases but also resulted in a gain of interest in IL-1 $\beta$ biology and its role in inflammatory disorders.

Since such a broad range of stimuli can activate the NLRP3 inflammasome, it is believed that a common mechanism triggered by diverse activators leads to NLRP3 activation. Several events such as the release of oxidized mitochondrial DNA (Shimada et al., 2012), production of reactive oxygen species (ROS) (Dostert et al., 2008), mitochondrial stress (Zhou et al., 2011), lysosomal rupture with cathepsin B release (Hornung et al., 2008), changes in intracellular calcium $\left(\mathrm{Ca}^{2+}\right)$ levels (Murakami et al., 2012) and potassium $\left(\mathrm{K}^{+}\right)$-efflux (Petrilli et al., 2007) have been reported to be associated to inflammasome activation (Figure 1). Whether all or only a part of these events are required for NLRP3 inflammasome activation is not clear. Munoz-Planillo et al. (2013) suggested that the sole reduction of intracellular $\mathrm{K}^{+}$was sufficient for NLRP3 inflammasome activation but recent reports have suggested that, in certain circumstances, inflammasome activation can occur independently of $\mathrm{K}^{+}$-efflux (Gross et al., 2016) or phagocytosis of bacteria (Chen et al., 2016). Moreover, the activity of the NRLP3 inflammasome has also been reported to be controlled by kinases such as Bruton's tyrosine kinase (BTK) interacting with NLRP3 and ASC thus favoring the recruitment of caspase-1 (Ito et al., 2015), and JNK or Syk kinases regulating ASC oligomerization (Hara et al., 2013; Okada et al., 2014). ROS were shown to activate NEK7, a kinase involved in the control of mitosis, causing its direct binding to the LRR domain of NLRP3 and modulating 


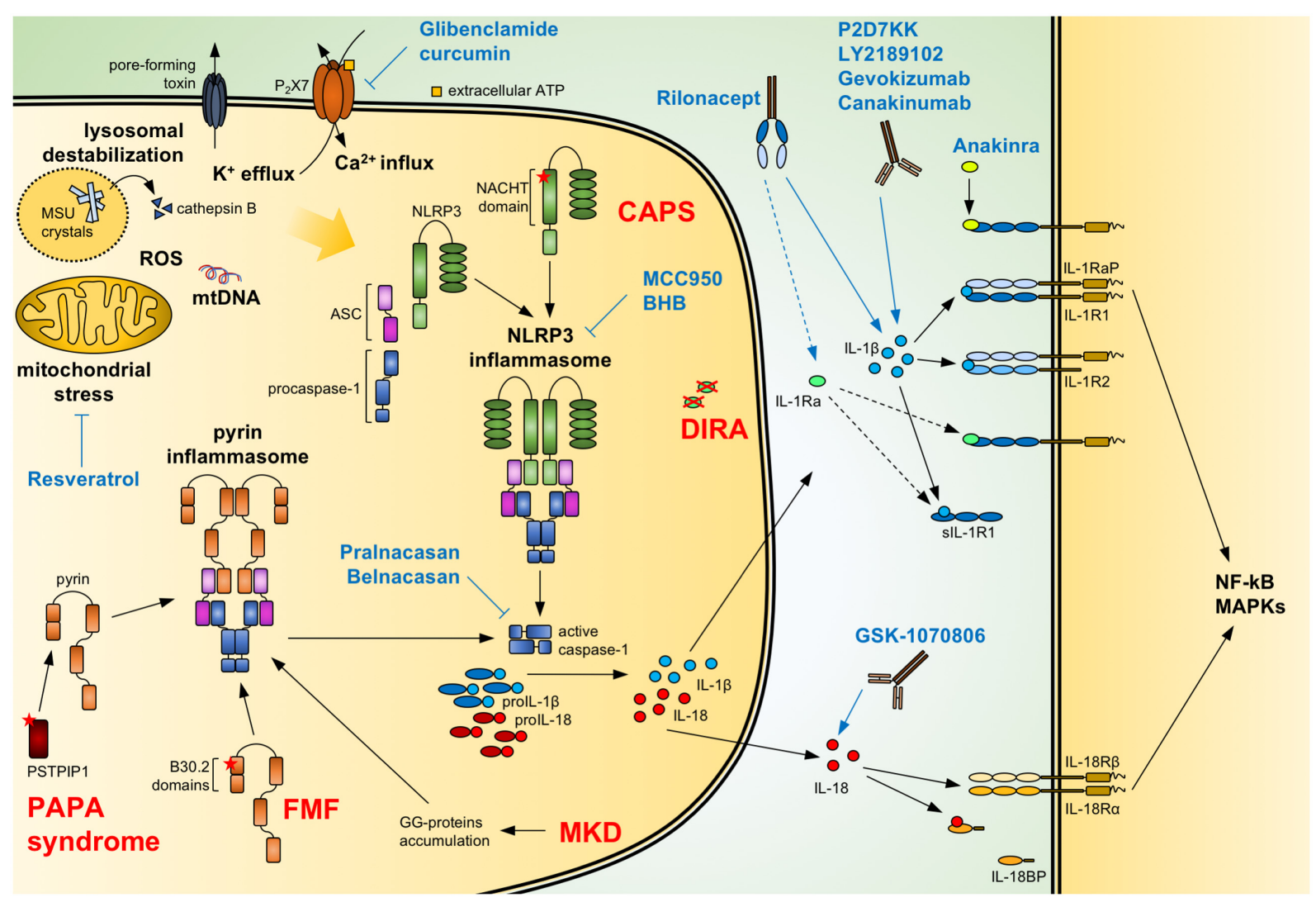

FIGURE 1 | Regulation of IL-1/18 production and current IL-1/18 antagonists. Pathogen- and danger-associated molecular patterns can induce the formation of a functional inflammasome via events including mitochondrial stress with release of oxidized mtDNA, ROS, lysosomal destabilization with cathepsin B release, changes in intracellular calcium $\left(\mathrm{Ca}^{2+}\right)$ and potassium $\left(\mathrm{K}^{+}\right)$efflux. Also, mutations of NACHT-PYD domains of NLRP3 in cryopyrin-associated periodic syndromes (CAPS) lead to the activation of the NLRP3 inflammasome. Similarly, mutations of B30.2 domains in familial Mediterranean fever (FMF) and of PSTPIP1 in PAPA syndrome or accumulation of geranylgeranylated proteins (GG-proteins) in mevalonate kinase deficiency (MKD) lead to activation of the pyrin inflammasome. Activated inflammasomes recruit procaspase- 1 via the adaptor ASC. Autocatalytically cleaved and activated caspase-1 can then process IL-1 $\beta$ and IL-18. The secreted cytokines bind to the IL-1 receptor (IL-1R1:IL-1RaP) and IL-18 receptor (IL-18R $\alpha: I L-18 R \beta)$, respectively, resulting in NF-kB and MAPKs signaling. Soluble IL-1R1 (sIL-1R1), IL-1R2 and IL-18 binding protein (IL-18BP) can block the signaling pathway. Caspase-1 activity can be modulated by the specific inhibitors Pralnacasan and Belnacasan. The activation of the NLRP3 inflammasome can be inhibited with Glibenclamide and curcumin inhibiting or downregulating the ATP-sensitive $\mathrm{K}^{+}$-channels $\mathrm{P}_{2} \mathrm{X}$, respectively; with Resveratrol increasing autophagy and inhibiting mitochondrial stress; and with the specific NLRP3 inhibitors MCC950 and BHB. Anakinra and the secreted IL-1 receptor antagonist (IL-1Ra), absent in deficiency of IL-1 receptor antagonist (DIRA) patients, compete with $\mathrm{IL}-1 \beta$ and IL-1 $\alpha$ (not shown) for binding to the IL-1 receptor. Rilonacept acts as a soluble decoy binding IL-1 $\beta$ and with lower affinity IL-1 $\alpha$ (not shown) and IL-1Ra. The recombinant antibodies Canakinumab, Gevokizumab, LY2189102, and P2D7KK specifically target and neutralize IL-1 $\beta$. Similarly, GSK-1070806 and MABp1 inhibits IL-18 and IL-1 $\alpha$ (not shown), respectively. Blue arrows: inhibitory effect; dotted arrow: low affinity; ASC, apoptosis associated speck-like domain protein containing a CARD; MSU, monosodium urate; mtDNA, mitochondrial DNA; ROS, reactive oxygen species.

its function (He et al., 2016; Shi et al., 2016). The consensual and unifying mechanism leading to NLRP3 inflammasome is currently a matter of intense debate and investigation.

The absent in melanoma 2 (AIM2) inflammasome recognizes viral and bacterial double-stranded DNA (dsDNA) via its PYHIN domain (Muruve et al., 2008). AIM2, like NLRP3, recruits caspase- 1 via the adaptor protein ASC. Increased levels of AIM2 were found in keratinocytes of patients with psoriasis and atopic dermatitis, causing acute and chronic skin barrier disruption-related inflammation (Ito et al., 2015).

The NLRC4 inflammasome is activated by bacterial flagellin (Mariathasan et al., 2004) and type 3 secretion system proteins (Miao et al., 2010). NLRC4 contains a CARD domain and is therefore able to recruit and activate caspase-1 without the adaptor ASC. Salmonella typhimurium is reported to activate NLRC4 by inducing its phosphorylation by protein kinase C $\delta$-type (PKC $\delta$ ) (Qu et al., 2012). Moreover, NLRC4 can recruit NLRP3 resulting in increased caspase-1 processing ( $\mathrm{Qu}$ et al., 2016). Reported NLRC4 gene mutations cause recurrent fever flares and macrophage activation syndrome (MAS) (Canna et al., 2014), neonatal-onset enterocolitis and fatal or near-fatal episodes of autoinflammation (Romberg et al., 2014). A missense mutation of NLRC4 was also associated with FCAS (Kitamura et al., 2014).

The pyrin inflammasome is encoded by the $M E F V$ gene and contains PYD, TRIM, and B30.2 domains. This inflammasome is activated by bacterial toxins like Clostridium difficile toxin B (TcdB) and C3 toxins (Park et al., 2016). Mutations in 
this gene are the cause of familial Mediterranean fever (FMF) (Chae et al., 2006) and the recently described disease-entity pyrin-associated autoinflammation with neutrophilic dermatosis (PAAND) (Masters et al., 2016). Mevalonate kinase deficiency (MKD) was also linked to the activation of the pyrin inflammasome (Park et al., 2016).

Other less characterized inflammasomes include NLRP2, NLRC2, NLRP6, NLRP7, and NLRP12. Besides their role in caspase-1 activation, they possess roles in activating/inhibiting $\mathrm{NF}-\kappa \mathrm{B}$ as well as MAPK pathways and autophagy (Lupfer and Kanneganti, 2013).

The involvement of caspase-5 in the processing of IL- 1 was already described in the original publication describing the inflammasome (Martinon et al., 2002), but it is only a decade later that its role in cell death was reported (Kayagaki et al., 2011, 2015). Human caspase-4, caspase-5 and the orthologous murine caspase-11 are activated by cytosolic LPS (Shi et al., 2014) and can cleave the substrate gasdermin D (GSDMD). GSDMD creates pores in the cell membrane resulting in pyroptosis, an inflammatory form of programmed cell death (He et al., 2015; Shi et al., 2015). Activated GSDMD can also induce the formation of the NLRP3 inflammasome and subsequent IL-1 $\beta$ and IL-18 secretion. This process known as the non-canonical inflammasome activation, can occur either in a caspase$1 /$ inflammasome-dependent or independent manner (Man and Kanneganti, 2016). Indeed, caspase-8, an initiator caspase mainly involved in apoptosis, can be involved in the activation of the NF- $\kappa \mathrm{B}$ pathway and IL-1 $\beta / \mathrm{IL}-18$ processing. Recognition by dectin-1 of extracellular fungi such as Candida albicans results in the formation of a complex with CARD9, Bcl-10, MALT1, ASC and caspase- 8 which, once activated, can directly process IL-1 $\beta$. Interestingly, dectin-1 dependent internalization of fungi drives instead the NLRP3 inflammasome (Gringhuis et al., 2012). Moreover, activation of caspase- 8 through the Fassignaling pathway can also lead to the direct processing of IL-1 $\beta$ and IL-18 independently of caspase-1 and ASC (Bossaller et al., 2012).
Other enzymes that are described to process IL-1 family members include neutrophil-derived elastase, cathepsin $G$ and proteinase 3 (myeloblastin), mast cell-derived chymase and granzyme B from cytotoxic lymphocytes and natural killer cells (Afonina et al., 2015).

\section{INHIBITION OF IL-1 SIGNALING}

\section{IL-1 $\beta$ Antagonists}

Given the key role of IL-1 $\beta$ in inflammatory and autoinflammatory disorders, several IL-1 inhibitors have been developed and evaluated especially in life-threatening autoinflammatory syndromes. To date, the most efficient way to block IL-1 signaling consists of biologics that specifically target IL-1 or IL-1R1 (Figure 1 and Table 1).

Anakinra (Kineret ${ }^{\circledR}$; Sobi, Inc.) is a recombinant nonglycosylated homolog of IL-1Ra that competes with both IL- $1 \alpha$ and IL- $1 \beta$ for the binding to IL-1R1 thus impairing the recruitment of IL-1RaP and downstream NF-кB/MAPKs signaling. It is the first biologic developed to specifically target IL-1. Anakinra was first approved in 2001 for the treatment of RA. A decade later, its use was extended to the treatment of cryopyrin-associated periodic syndromes (CAPS) in Europe and for the severest form of CAPS, namely chronic infantile neurological cutaneous and articular syndrome (CINCA) in the USA. Anakinra has a short halflife of $4-6 \mathrm{~h}$ and therefore common posology requirements are daily subcutaneous injections of $100 \mathrm{mg} /$ day for RA and 1-2 mg/kg/day for CINCA.

Rilonacept (Arcalyst ${ }^{\circledR}$; Regeneron) is a long-acting dimeric fusion protein consisting of portions of IL-1R1 and IL-1RaP linked to the Fc portion of human immunoglobulin G1 (IgG1). Rilonacept acts a soluble decoy binding IL-1 $\beta$, but also IL$1 \alpha$ and IL-Ra, therefore inhibiting their association with cell surface receptors (IL-1Trap). Rilonacept binds three times stronger to IL- $1 \beta$ than to IL- $1 \alpha$ and 12 times stronger to

TABLE 1 | Biologics and inhibitors of IL-1, IL-18, and inflammasome activation.

\begin{tabular}{|c|c|c|c|c|c|c|}
\hline Name & Trade name & Company & Class & Target & $h_{1 / 2}$ & Status \\
\hline Anakinra & Kineret ${ }^{\circledR}$ & Sobi, Inc. & reclL-Ra & $\mathrm{IL}-1 \alpha, \mathrm{IL}-1 \beta$ & $4-6$ hours & Marketed \\
\hline Rilonacept & Arcalyst ${ }^{\circledR}$ & Regeneron & srR (IL-1Trap) & $\mathrm{IL}-1 \alpha, \mathrm{IL}-1 \beta, \mathrm{IL}-\mathrm{Ra}$ & $\sim 7.5$ days & Marketed \\
\hline Canakinumab (ACZ855) & llaris $^{\circledR}$ & Novartis & $\mathrm{mAb}(\operatorname{lgG} 1 / \kappa)$ & IL-1 $\beta$ & 23-26 days & Marketed \\
\hline Gevokizumab (XOMA 052) & & XOMA & $\mathrm{mAb}(\operatorname{lgG} 2 / \kappa)$ & $\mathrm{IL}-1 \beta$ & 22 days & Phase $3^{\dagger}$ discontinued \\
\hline LY2189102 & & Eli Lilly and Co & mAb (lgG4) & $\mathrm{IL}-1 \beta$ & 16.8 days & Phase 2 \\
\hline P2D7KK & & A*STAR & mAb (lgG1) & $\mathrm{IL}-1 \beta$ & 〜2 weeks* & Preclinical \\
\hline Pralnacasan (VX-740) & & Vertex & SMI & Caspase-1 & nd & Phase $2^{\dagger}$ \\
\hline Belnacasan (VX-765, HMR3480) & & Vertex & SMl & Caspase-1 & nd & Phase $2^{\dagger}$ \\
\hline MCC950 & & & SMl & NLRP3 & nd & Preclinical \\
\hline $\mathrm{BHB}$ & & & SMl & NLRP3 & nd & Preclinical \\
\hline Glibenclamide (glyburide) & Generic & & SMl & $K_{A T P}$ & 10 hours & Marketed \\
\hline MABp1 & Xilonix $^{\mathrm{TM}}$ & XBiotech & $\mathrm{mAb}(\operatorname{lgG} 1 / \kappa)$ & $\mathrm{IL}-1 \alpha$ & 8 days & Phase $3^{\ddagger}$ Phase 2 \\
\hline GSK-1070806 & & GlaxoSmith-Kline & $\mathrm{mAb}(\operatorname{lgG} 1 / \kappa)$ & IL-18 & 23-30 days & Phase 2 \\
\hline
\end{tabular}

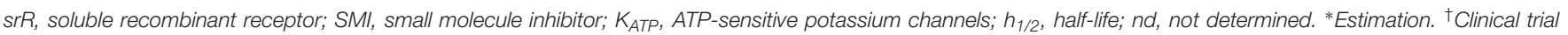
was terminated. ${ }^{\ddagger}$ Only for the treatment of colorectal and non-small cell lung cancers. 
IL- $1 \beta$ than to IL-1Ra. It was approved by the FDA in 2008 for the treatment of CAPS including FCAS and Muckle-Wells syndrome (MWS). Rilonacept has a half-life of 6.3-8.6 days which allows a weekly subcutaneous administration of $320 \mathrm{mg}$ (loading dose) followed by weekly injections of half the loading dose.

Canakinumab (ACZ885, Ilaris ${ }^{\circledR} ;$ Novartis) is a human anti-IL1 $\beta$ monoclonal IgG1/ $\kappa$ isotype antibody with a terminal half-life of 23-26 days and can be therefore administered as a single subcutaneous injection every 2 months.

Canakinumab was approved by the FDA in 2009 for the treatment of CAPS and active systemic juvenile idiopathic arthritis. Recently, it received approval from the FDA as first-line treatment for TNF receptor associated periodic syndrome (TRAPS), MKD and FMF (FDA, 2016).

Gevokizumab (XOMA 052; XOMA) is a recombinant humanized anti-IL-1 $\beta$ antibody. In contrast to Canakinumab, which neutralizes IL-1 $\beta$ by competing for binding to IL$1 \mathrm{R}$, Gevokizumab modulates IL- $1 \beta$ bioactivity by reducing its affinity for IL-1R1:IL-1RAcP signaling complex (Blech et al., 2013).

The clinical development of this antibody was interrupted in 2016 after a phase 3 clinical trial evaluating Gevokizumab for the treatment of uveitis in patients with Behçet's disease did not meet the primary endpoint criteria (Xoma, 2015, 2016).

Gevokizumab showed promising results in phase 2 trial on acne vulgaris (Xoma, 2013) but failed to show benefits in the treatment of pyoderma gangrenosum (Xoma, 2016).

LY2189102 (Eli Lilly and Co) is a high affinity anti-IL-1 $\beta$ humanized monoclonal immunoglobulin G4 with a terminal half-life of 16.8 days (Bihorel et al., 2014). A weekly treatment of patients suffering from type 2 diabetes mellitus (T2DM) with LY2189102 for 3 months resulted in modest reductions in glycated hemoglobin and blood glucose (Sloan-Lancaster et al., 2013). No further studies have been conducted to date.

P2D7KK is another neutralizing monoclonal antibody against IL-1 $\beta$ developed by $A^{*}$ STAR researchers in Singapore. It shares the same mechanism of action as Canakinumab but with an in vitro neutralization potency that is 11 times higher. P2D7KK has not been evaluated in human subjects yet but has shown promising effects in three different inflammatory animal models (Goh et al., 2014).

Virus-like particles (VLPs)-based vaccination constitutes a novel approach to target cytokines (Assier et al., 2017). Recombinant mutated IL- $1 \beta$ chemically cross-linked to bacteriophage $\mathrm{Q} \beta$ VLPs $(\mathbf{h I L} \mathbf{1} \beta \mathbf{Q} \beta)$ was investigated in a phase 1 clinical trial for T2DM resulting in safe production of specific IL-1 $\beta$ antibodies in the treated patients (Cavelti-Weder et al., 2016).

\section{Inflammasome Inhibitors}

Other possibilities to block IL-1 $\beta$ include the targeting of caspase-1 and NLRP3. Two caspase-1 inhibitors have been developed, namely Pralnacasan (VX-740) and Belnacasan (VX-765, also HMR3480) (Vertex Pharmaceuticals). These orally absorbed compounds are synthetized as prodrugs which are then converted into the active principle, VRT-018858 and VRT-043198, respectively.

Pralnacasan has been evaluated in clinical trials for the treatment of RA and osteoarthritis but due to safety issues its development has been interrupted (Braddock and Quinn, 2004; Vertex, 2007).

Belnacasan was shown to inhibit IL-1 $\beta$ and IL-18 release from PBMCs of FCAS patients in vitro (Stack et al., 2005). It induces anti-inflammatory effects in a mouse model of delayedtype hypersensitivity (DTH) (Wannamaker et al., 2007) and it has been evaluated in phase 1 and 2 a clinical trials in the setting of epilepsy and psoriasis (Vertex, 2011).

NLRP3 inhibitors include MCC950, $\beta$-hydroxybutyrate and glibenclamide. MCC950 is a small-molecule able to block canonical and non-canonical NLRP3-induced ASC oligomerization without interfering with NLRC4 and AIM2 activity or TLR signaling (Coll et al., 2015). MCC950 has been shown to be effective for the treatment of CAPS in mice harboring activating Nlrp3 mutations (Coll et al., 2015) and in mouse models of dermal and airway inflammation (Primiano et al., 2016). $\beta$-hydroxybutyrate (BHB) is an anti-inflammatory molecule that specifically targets NLRP3 activity. In murine models of FCAS and MWS, BHB inhibited constitutive NLRP3 inflammasome activation (Youm et al., 2015). Glibenclamide (glyburide), is an anti-diabetic drug used in the treatment of T2DM. It inhibits the ATP-sensitive $\mathrm{K}^{+}$channel and was shown to block the NLRP3 inflammasome activation induced by LPS, ATP, nigericin and silica (Lamkanfi et al., 2009). These inhibitors present a potential advantage in the treatment of CAPS since they specifically target the NLRP3 inflammasome impacting both IL- $1 \beta$ and IL- 18 secretion.

Resveratrol and curcumin are natural polyphenols found in several plants and are able to block IL- $1 \beta$ secretion. Resveratrol was described to inhibit NLRP1, NLRP3, and NLRC4 activation by preventing mitochondrial damage and augmenting autophagy (Chang et al., 2015). Moreover, Resveratrol was shown to directly bind and block COX-2 activity (Zykova et al., 2008) which is known to be involved in NLRP3 activation (Hua et al., 2015). Curcumin has been shown to impair IL-1 $\beta$ secretion in PMA-treated macrophages by downregulating $\mathrm{P}_{2} \mathrm{X}_{7}$ receptor and thus inhibiting the TLR4/MyD88/NF- $\kappa$ B pathway (Kong et al., 2016).

\section{IL-1 $\alpha$ and IL-18 Blockers}

In contrast to IL- $1 \beta$, the development of IL- $1 \alpha$ and IL-18 inhibitors is less advanced. The monoclonal antibody against IL-1 $\alpha$, MABp1 (Xilonix ${ }^{\mathrm{TM}}$; XBiotech) is the only biologic that specifically target this cytokine and it is currently under investigation for the treatment of advanced cancer (Hong et al., 2014; Hickish et al., 2017).

MABp1 has been evaluated for the treatment of psoriasis (Coleman et al., 2015), acne vulgaris (Carrasco et al., 2015), T2DM (Timper et al., 2015) and is currently being evaluated in patients with hidradenitis suppurativa (HS) who were refractory to anti-TNF $\alpha$ treatment (discussed below).

The only agent targeting the cytokine IL-18 is the GSK-1070806 antibody (GlaxoSmithKline). In a study for 
the treatment of T2DM, GSK-1070806 did not reveal any improvement in glucose control (McKie et al., 2016). However, neutralization of IL-18 was shown to reduce the severity of dextran sulfate sodium-induced colitis in mice (Siegmund et al., 2001; Sivakumar et al., 2002).

\section{SKIN DISEASES WITH IL-1 INVOLVEMENT}

Keratinocytes are the most abundant cells in the skin and act as a barrier against water loss and entry of pathogens and irritants. Human keratinocytes constitutively express IL- $1 \alpha$, IL- $\beta$, and IL-18 and possess all inflammasome components (Feldmeyer et al., 2007).

Inflammation in the skin with extensive release of IL-1 $\beta$ is often associated with neutrophilic infiltration as first line of defense. In the absence of infection, neutrophils can become detrimental for the host by causing tissue damage (Navarini et al., 2016).

\section{Monogenic Autoinflammatory Diseases}

Monogenic autoinflammatory diseases are a rare group of hereditary syndromes with early manifestation in childhood. They present as inflammatory recurrent flares of fever and skin lesions. Neutrophilic dermatosis is the most common pathological hallmark of these syndromes (Lipsker et al., 2016).

Cryopyrin-associated periodic syndromes are disorders caused by mutations in the NLRP3 gene, previously known as cold-induced autoinflammatory syndrome 1, which results in uncontrolled processing of IL-1 $\beta$ and IL-18 (Figure 1). CAPS is a spectrum of three syndromes of increasing severity: familial cold autoinflammatory syndrome (FCAS, OMIM \#120100), Muckle-Wells syndrome (MWS, OMIM \#191900) and chronic infantile neurological cutaneous and articular syndrome (CINCA, OMIM \#697115) also known as neonatal-onset multisystem inflammatory disease (NOMID). They phenotypically share episodes of recurring fever, urticarialike skin-lesions, conjunctivitis and inflammatory joint pain. In MWS and CINCA, progressive hearing loss and eye inflammation occur; in CINCA, the most severe form of CAPS, central nervous system inflammation is the most devastating symptom leading to increased intracranial pressure and aseptic meningitis (Goldbach-Mansky, 2011). The mutations in the NLRP3 gene causing FCAS, MWS and CINCA were identified long before the discovery of the inflammasome (Hoffman et al., 2001; Aksentijevich et al., 2002). To date, 182 mutations in the NLRP3 gene have been reported in the online registry of hereditary autoinflammatory disorders mutations (Infevers, 2017).

Mouse models for FCAS and MWS were generated by knocking-in NLRP3 with a L351P and A350V mutation, respectively. Mating of these mice with $I l 1 r 1^{-/-}$mice confirmed the pivotal role of IL- $1 \beta$ in the pathogenesis of these diseases but did not completely rescue the phenotype suggesting a possible IL-18 involvement (Brydges et al., 2009). Generation of FCAS mice lacking both IL-1 and IL-18 receptors did not prevent the mice from succumbing to the disease; this could be explained by residual inflammation due to increased pyroptosis (Brydges et al., 2013).

Although mutations in NLRP3 gene are the major cause of CAPS, mutation in NLRC4 and NLRP12 have also been reported in few cases (Jeru et al., 2008; Kitamura et al., 2014).

Biologics against IL- $1 \beta$ have revealed successful in the treatment of CAPS. In 2003, a remarkable response after 6 months treatment with $100 \mathrm{mg} /$ day of Anakinra, as was reported in two MWS patients (Hawkins et al., 2003). Anakinra was later revealed to be successful for the treatment of FCAS (Hoffman et al., 2004) and CINCA (Lovell et al., 2005). In a first clinical trial, 18 patients with CINCA received injections of $1-2 \mathrm{mg} / \mathrm{kg} /$ day Anakinra resulting in a rapid response in all patients (ClinicalTrials.gov Identifier: NCT00069329) (Goldbach-Mansky et al., 2006). Withdrawal of treatment resulted in relapse of the disease within days and re-administration recovered the drug's effects. Another open-label study proved the efficacy of Anakinra treatment in 5 FCAS patients over a period of 16 months (ClinicalTrials.gov Identifier: NCT00214851) (Ross et al., 2008).

In an open-label study, five patients with FCAS received a $300 \mathrm{mg}$ loading dose of Rilonacept, resulting in improvement of all symptoms within days of drug administration (ClinicalTrials.gov Identifier: NCT00094900) (GoldbachMansky et al., 2008). Under treatment with $100 \mathrm{mg} /$ week (max. $320 \mathrm{mg} /$ week) symptoms were under control in all patients for 24 months. In a randomized double-blind, placebo controlled clinical trial, 47 patients with FCAS and MWS were enrolled and injected weekly with $160 \mathrm{mg}$ Rilonacept for 6 weeks. Ninety-six percent of the patients receiving Rilonacept experienced at least a $30 \%$ reduction in the mean key symptom score in contrast to $29 \%$ of patients receiving placebo (ClinicalTrials.gov Identifier: NCT00288704) (Hoffman et al., 2008).

Neutralization of IL-1 $\beta$ with Canakinumab for the treatment of CAPS was first described in a phase 3 study involving 35 patients. In the first open-label part, all patients received a single subcutaneous $150 \mathrm{mg}$ Canakinumab injection: 34 individuals had a complete response at day 29. In the second, double-blind, placebo-controlled, randomized withdrawal part of the study, all patients receiving the drug remained in remission whereas 13 out of 16 patients receiving placebo experienced a disease flare. In the third and final open-label part, all enrolled patients received Canakinumab and 97\% sustained clinical and biochemical remission at the end of the study (ClinicalTrials.gov Identifier: NCT00465985) (Lachmann et al., 2009). Several other studies support the efficacy of Canakinumab in the treatment of CAPS. In an open-label, phase 3 study with 166 patients, $78 \%$ of Canakinumab-naïve patients had a complete response and $90 \%$ of the assessed patients were relapse-free over the study period (ClinicalTrials.gov Identifier: NCT00685373) (Kuemmerle-Deschner et al., 2011a). In another study, pediatric MWS and CINCA patients achieved complete response within 1 week after the first Canakinumab injection (ClinicalTrials.gov Identifier: NCT00487708) (Kuemmerle-Deschner et al., 2011b). An additional report revealed that treatment with Canakinumab 
of CINCA resulted in clinical improvement in five out of six patients but none experienced a full remission (ClinicalTrials.gov Identifier: NCT00770601) (Sibley et al., 2015). Recently, a long-term (26 months) open-label study of 19 CAPS patients, revealed that $95 \%$ of the patients were relapse-free at the end of the study and the treatment was well tolerated (ClinicalTrail.gov Identifier: NCT00991146) (Yokota et al., 2016). Finally, results from the $\beta$-confident register enrolling 288 CAPS patients showed sustained safety of Canakinumab over a follow up period of up to 5 years. Eighty-six patients experienced severe adverse reactions but only five discontinued the treatment (Hoffman et al., 2016, meeting abstract) (ClinicalTrail.gov Identifier: NCT01213641).

Extensive studies on the pathogenesis of CAPS have revealed how mutant NLRP3 has defective interaction with the IL-1 $\beta$ maturation inhibitor cyclic AMP (Lee et al., 2012) or with its negative regulator CARD8 (Ito et al., 2014). Small molecule inhibitors were shown to be beneficial in mice models of FCAS and MWS; the anti-inflammatory molecule BHB inhibits constitutive NLRP3 inflammasome activity (Youm et al., 2015). Additionally, the specific NLRP3 inhibitor MCC950 showed efficacy in mouse models of CAPS harboring activating NLRP3 mutations (Coll et al., 2015), and in mouse models for dermal and airway inflammation (Primiano et al., 2016).

Familial Mediterranean fever (FMF, OMIM \#249100) is an autosomal recessive disorder caused by gain-of-function mutations in the $M E F V$ gene encoding pyrin (French FMF Consortium, 1997). Pyrin contains a 14-3-3 binding motif which, when phosphorylated, regulates the compartmentalization (Jeru et al., 2005) and inhibits the activity of pyrin (Park et al., 2016). Pyrin mutations or inactivation of effector kinases by bacterial toxins leave the protein unphosphorylated and free to form a pyrin-inflammasome and activate caspase- 1 (Chae et al., 2006; Figure 1). The current first-line treatment for FMF is colchicine, which, via RhoA effector kinases, can lead to pyrin phosphorylation and result in its inactivation (Park et al., 2016). Symptoms of FMF include periodic fever attacks, abdominal and chest pain, serositis, amyloidosis and cutaneous inflammation (Jesus and Goldbach-Mansky, 2014). Recently, a specific dominantly inherited S242R mutation in the 14-3-3 binding motif has been identified and shown to result in pyrin-associated autoinflammation with neutrophilic dermatosis (PAAND), an autoinflammatory disease with distinct clinical features such as severe recurrent neutrophilic dermatosis, fever and absence of serositis and amyloidosis (Masters et al., 2016).

In 2008, treatment of FMF using IL-1 $\beta$ antagonists was first reported in patient that received $50 \mathrm{mg} /$ day Anakinra subcutaneously without interrupting colchicine. Fever attacks and chest pain were reduced during Anakinra treatment but reappeared upon discontinuation (Calligaris et al., 2008). Recent results of a double-blind, placebo-controlled, randomized study involving 14 colchicine-resistant FMF patients showed that those who received Anakinra daily at a subcutaneous dosage of $100 \mathrm{mg}$ had significantly less fever attacks per month (1.7 vs. 3.5 in the placebo group) (ClinicalTrials.gov Identifier: NCT01705756) (Ben-Zvi et al., 2017).

Previously, Rilonacept was also shown to be a possible treatment option for colchicine-resistant or -intolerant FMF patients: in a small randomized, double-blind, alternating treatment study, Rilonacept given at $2.2 \mathrm{mg} / \mathrm{kg}$ weekly reduced the attack frequency to 0.77 per month in comparison to 2 per month in the placebo-treatment group. (ClinicalTrials.gov Identifier: NCT00582907) (Hashkes et al., 2012).

IL-1 $\beta$ inhibition with Canakinumab was also reported to be effective in colchicine-resistant FMF patients. In a 6-month, phase 2, open-label, single-arm study, seven children who experienced FMF attacks under daily colchicine treatment received three monthly subcutaneous injections of Canakinumab $(2 \mathrm{mg} / \mathrm{kg})$. The median attack rate per month decreased from 2.7 to 0.3 during the treatment period (ClinicalTrials.gov Identifier: NCT01148797) (Brik et al., 2014). In a second study, nine patients received three consecutive injections of $150 \mathrm{mg}$ Canakinumab every 4 weeks. During the treatment period, only one patient had an attack (peritonitis) and five patients experienced an attack in the 2-months follow up period (ClinicalTrials.gov Identifier: NCT01088880) (Gül et al., 2015). In a retrospective longitudinal outcome study, the effects of long-term Canakinumab treatment in 14 colchicine-resistant FMF patients were assessed. All patients responded to the treatment but four relapsed during the followup. The shortening of Canakinumab administration intervals from $8 / 6$ weeks to 4 weeks resulted in partial to full clinical remission (Laskari et al., 2017).

Deficiency of IL-1 receptor antagonist (DIRA, OMIM \#612852) is very rare autoinflammatory disease with onset in the neonatal period and presents as systemic inflammation, pustular skin lesions, joint swelling, periostitis and multifocal osteomyelitis (Altiok et al., 2012). DIRA is caused by homozygous mutations in the $I L I R N$ gene. It was first described in nine children harboring mutations leading to the synthesis of a truncated non-functional form of IL-1Ra (Aksentijevich et al., 2009; Figure 1). Around the same time, another group reported the case of a 49 -day-old baby presenting a 175 -kb homozygous deletion in chromosome 2 which was spaced over six IL-1 family members including ILIRN. This patient completely recovered after Anakinra treatment (Reddy et al., 2009). Another case report described the positive response to Anakinra in a 3 month-old child with confirmed DIRA (Schnellbacher et al., 2013).

More recently, treatment of a 12 year-old child suffering from DIRA due to a novel IL1RN mutation with $150 \mathrm{mg}$ Canakinumab given every 6 weeks led to complete remission without side effects (Ulusoy et al., 2015).

A pilot open-label study to assess the efficacy of Rilonacept treatment for DIRA was completed in April 2016 but results are yet to be published (ClinicalTrials.gov Identifier: NCT01801449). Preliminary data on safety and efficacy in six patients suggests that a weekly injection of $4.4 \mathrm{mg} / \mathrm{kg}$ Rilonacept is required to achieve remission (Neal et al., 2014, meeting abstract).

Tumor Necrosis Factor Receptor Associated Periodic Syndrome (TRAPS, OMIM \#142680) is an autosomal dominant inherited disorder linked to mutations of TNFRSF1A gene encoding the TNF $\alpha$ receptor 1 (McDermott et al., 1999; Hull et al., 2002). These mutations produce a misfolded receptor defective in shedding that accumulates in the cytoplasm and results in enhanced NF- $\mathrm{B}$ activation, ROS production and 
impaired autophagy (Bachetti and Ceccherini, 2014). TRAPS symptoms include long-lasting (more than 1 week) fever associated with abdominal pain, skin lesions, and serositis. Various types of skin lesions occur, most frequently erythematous patches and plaques that can be migratory and associated with underlying myalgia.

Anti-TNF treatments were shown to be partially beneficial in TRAPS but may also cause paradoxical inflammatory attacks (Drewe et al., 2007). In contrast, IL-1 blockade seems to be more beneficial. Indeed, remarkable improvement was reported in TRAPS patients treated with Anakinra (Simon et al., 2004; Gattorno et al., 2008; Greco et al., 2015). Specifically targeting IL-1 $\beta$ was also shown to be successful for the treatment of TRAPS. In 2012, it was first reported that a woman who was taken off anti-TNF treatment and received $150 \mathrm{mg}$ Canakinumab every 8 weeks instead, had complete remission (Brizi et al., 2012). Recently, the results of an open-label, proof-of-concept, phase 2 study were released: 20 patients received $150 \mathrm{mg}$ Canakinumab every 4 weeks for 4 months. 19/20 patients achieved clinical remission at day 15 and all relapsed after withdrawal of the drug (ClinicalTrials.gov Identifier: NCT01242813) (Gattorno et al., 2017). Interestingly, a mutation or duplication of the TNFRSF11A gene coding for the receptor RANK was associated in three patients with recurrent episodes of fever. Analysis of serum from one patient revealed increased levels of inflammatory cytokines and particularly an eightfold increase for IL-18 (Jeru et al., 2014).

Mevalonate kinase deficiency (MKD) is an autosomal recessive metabolic disorder caused by mutations in the $M V K$ gene (Haas and Hoffmann, 2006). Mevalonate kinase is an enzyme involved in the synthesis of cholesterol and isoprenoids. Mutations in this gene lead to shortage of geranylgeranylated proteins which cause the activation of the pyrin inflammasome and subsequent secretion of IL-1 $\beta$ (Mandey et al., 2006; van der Burgh et al., 2013; Park et al., 2016; Figure 1). Two forms of the disease exist. The less severe hyperimmunoglobulinemia D syndrome (HIDS; OMIM \#260920) is characterized by sporadic fever episodes with skin lesions (widespread erythematous macules and papules), lymphadenopathy, abdominal and joint pain, diarrhea and headache (van der Meer et al., 1984). The rare, more severe form of the disease mevalonic aciduria (MVA; OMIM \#610377) presents all above symptoms chronically (Berger et al., 1985).

In 2005, the case of a 38-year-old HIDS patient with recurrent fever episodes with symptom normalization following $100 \mathrm{mg} /$ day Anakinra treatment was reported (Bodar et al., 2005). As fever episodes in HIDS occur at irregular intervals of 2-8 weeks (van der Burgh et al., 2013), Anakinra treatment "on-demand" appears to be an optimal mode of management with significant clinical response in 8 out 12 attacks (Bodar et al., 2011). Treatment of HIDS with Canakinumab was first reported in a 7 -year-old child where $4 \mathrm{mg} / \mathrm{kg}$ administered every 4 weeks resulted in the prevention of fever attacks (Tsitsami et al., 2013). Recently, a retrospective study of $144 \mathrm{MKD}$ patients described the response to different therapeutic approaches, including IL-1 antagonists. Anakinra given only during attacks resulted in three complete and five partial responses whereas out of the 19 patients who received Anakinra as maintenance therapy, 3 exhibited a complete remission, 13 a partial remission and 3 did not respond. Canakinumab led to complete remission in four patients and partial remission in a patient resistant to all other therapies (Ter Haar et al., 2016). In an open-label, single treatment arm study, 9 HIDS patients received Canakinumab every 6 weeks for 6 months followed by a withdrawal phase lasting up to 6 months and a 24 month-long-term treatment period. Canakinumab treatment reduced the frequency of flares from a median of 5 flares to 0 (unpublished results; Aróstegui et al., 2015, oral presentation) (ClinicalTrials.gov Identifier: NCT01303380).

PAPA syndrome (pyogenic arthritis, pyoderma gangrenosum, and acne, OMIM \#604416) is a hereditary autosomal dominant autoinflammatory syndrome caused by gain-of-function mutations in the PSTPIP1 gene (Lindor et al., 1997; Wise et al., 2002). The resulting mutated protein interacts with, and activates pyrin, causing dysregulated processing of IL-1 $\beta$ and IL-18 (Shoham et al., 2003; Figure 1). PAPA syndrome is characterized by early onset of recurrent sterile arthritis with neutrophilic infiltrates, with variable skin involvement including pyoderma gangrenosum and severe nodulo-cystic acne in adolescence and beyond.

In the first report of PAPA, Anakinra was administered to control arthritis flares in patients presenting the PAPA mutation while not presenting PG symptoms (Dierselhuis et al., 2005). Efficacy of Anakinra was subsequently reported again in a patient presenting the triad of symptoms; after 5 days of daily Anakinra administration at $100 \mathrm{mg}$ per day, the skin lesions improved and after 1 month the ulcer due to PG completely healed with concomitant disappearance of arthritis and acne (Brenner et al., 2009).

The use of Canakinumab for the treatment of PAPA has also been reported: $150 \mathrm{mg}$ Canakinumab given every 8 weeks led to complete healing of PG and disappearance of acne lesions in a single patient (Geusau et al., 2013). IL-18 levels were reported to be elevated in a PAPA syndrome patient treated with cyclosporine. Although PG was treated, acne and splenomegaly were not, suggesting a possible role for IL-18 (Kanameishi et al., 2016). The treatment of PAPA syndrome is challenging, however, since the response to therapy varies largely between patients.

Blau syndrome (BS, OMIM \# 186580) is an autosomal dominant granulomatous disease caused by a mutation in CARD15/NOD2 gene (Miceli-Richard et al., 2001). NOD2 is an intracellular receptor able to sense the bacterial peptidoglycan MDP (McDermott et al., 1999), and signals via the NF-кB pathway (Franchi et al., 2009). Mutations of NOD2 are also linked to Crohn's disease (CD; OMIM \#266600) and early-onset sarcoidosis (EOS, OMIM \#609464); in EOS and BS, mutations in the nucleotide-binding oligomerization domain results in increased NF- $\kappa$ B activity (Maekawa et al., 2016).

IL-1 $\beta$ inhibition was shown in individual case reports to be useful for the treatment of BS. Indeed, a patient treated with Anakinra exhibited inflammatory symptom improvement and normalization of plasma cytokine levels (Aróstegui et al., 2007). The use of Canakinumab was also reported for the treatment of Blau syndrome-related uveitis in a young patient and resulted in 
disease remission and stabilization of proinflammatory cytokine expression comparable to that seen in healthy controls (Simonini et al., 2013).

\section{Polygenic Autoinflammatory Diseases and Chronic Inflammatory Diseases}

PASH syndrome (pyoderma gangrenosum, acne, and suppurative hidradenitis) is an autoinflammatory syndrome similar to but distinct from PAPA. It was first described in two patients presenting both pyoderma gangrenosum and acne without suffering from pyogenic arthritis (Braun-Falco et al., 2012). The genetic background of PASH syndrome is very heterogeneous; the absence of a PSTPIP1 gene mutation was first reported, however, researchers recently found a PSTPIP1 gene mutation in a PASH patient (Calderon-Castrat et al., 2016). Moreover, mutations in other genes involved in this autoinflammatory disease including NLRP3, MEFV, NOD2, and NCSTN have also been described in PASH (Marzano et al., 2014a; Duchatelet et al., 2015).

Treatment of PASH with Anakinra was reported in only one patient and resulted in partial remission (Braun-Falco et al., 2012).

In addition to PAPA and PASH, other phenotypically related syndromes are emerging. They include PASS (pyoderma gangrenosum, acne, suppurative hidradenitis, and axial spondyloarthritis), PAPASH (pyogenic arthritis, pyoderma gangrenosum, acne, and HS) and PsAPASH (psoriatic arthritis, pyoderma gangrenosum, acne, and HS) (Bruzzese, 2012; Marzano et al., 2013; Saraceno et al., 2015). Recently, a PASS patient treated with $100 \mathrm{mg} /$ day Anakinra and improvement of all symptoms was reported, after Anakinra discontinuation relapse occurred within 3 days (Leuenberger et al., 2016).

Schnitzler syndrome $(\mathrm{SchS})$ is a rare late-onset inflammatory disease considered as a sporadic acquired autoinflammatory disorder characterized by recurrent fever, urticarial skin lesions, arthritis and lymphadenopathy accompanied with IgM gammopathy. Treatment with Anakinra was reported to completely abrogate the symptoms within $24 \mathrm{~h}$ in several case reports (de Koning et al., 2006; Dybowski et al., 2008; Sonnichsen et al., 2016).

In a prospective, open-label study, all patients receiving Rilonacept for up to 1 year showed a rapid clinical response over the treatment duration with nearly complete remission in four of eight patients (ClinicalTrials.gov Identifier: NCT01045772) (Krause et al., 2012).

Canakinumab treatment in SchS was first positively reported in a patient switching from Anakinra (de Koning et al., 2011). In an open-label, single-treatment arm trial, eight additional patients switched from Anakinra to monthly injections of $150 \mathrm{mg}$ Canakinumab for 6 months. Clinical remission was observed in all patients at day 14 and lasted up to 6 months (full duration of the trial) in seven out of eight patients (ClinicalTrials.gov NCT01276522) (de Koning et al., 2013). In another case, injection of Canakinumab every 8 weeks resulted in the disappearance of the symptoms until drug withdrawal (ClinicalTrials.gov Identifier: NCT01245127) (Vanderschueren and Knockaert,
2013). Recently, a phase 2, randomized placebo-controlled, multi-center trial including 20 patients confirmed the potential of Canakinumab for the treatment of SchS. 7 days after initial injection, 5/7 patients who received the drug showed significant improvement when compared to placebo treated patients $(0 / 13)$. In the open-label trial phase, all patients received Canakinumab, and after 14 days, 15/20 exhibited complete remission and 5 partial remission (ClinicalTrials.gov Identifier: NCT01390350) (Krause et al., 2017).

Hidradenitis suppurativa (HS; OMIM \#142690, \#613736, \#613737), also known as acne inversa, is a chronic skin disease of the hair follicles affecting the axillary, inguinal and anogenital regions with formation of nodules and abscesses (Kurzen et al., 2008). Mutations in the $\gamma$-secretase genes NCSTN, PSENEN, and PSEN1 impairing the Notch signaling in hair follicles have been found in some HS patients (Pink et al., 2012). TNF- $\alpha$, IL-1 $\beta$, and IL-10 levels were frequently increased in HS lesions (van der Zee et al., 2011). Moreover, IL-17, caspase-1 and NLRP3 are elevated in lesions of HS skin (Lima et al., 2016).

The use and success of Anakinra for the treatment of HS has been a matter of controversy (van der Zee and Prens, 2013; Zarchi et al., 2013; Leslie et al., 2014; Menis et al., 2015; Russo and Alikhan, 2016). However, in a recent double-blind, randomized, placebo controlled trial, 20 patients were treated with Anakinra or placebo daily for 12 weeks. HS clinical response after 12 weeks was $78 \%$ in Anakinra-treated patients versus 30\% in the placebo group (ClinicalTrials.gov Identifier: NCT01558375) (Tzanetakou et al., 2016).

Treatment with Canakinumab was reported in one HS patient with concomitant PG. HS healed after the first injection and PG after 4 months of treatment (Jaeger et al., 2013). Recently a double-blind, randomized, placebo-controlled clinical trial investigating the efficacy of anti-IL- $1 \alpha$ therapy in HS patients who were refractory to anti-TNF drugs was completed. Patients receiving MaBp1 every 2 weeks for 12 weeks showed a $60 \%$ response rate in comparison to $10 \%$ in the placebo group (ClinicalTrials.gov Identifier: NCT02643654) (Xbiotech, 2017).

SAPHO syndrome (synovitis, acne, pustulosis, hyperostosis, osteitis) is a chronic inflammatory disorder targeting bones, skin and joints (Chamot et al., 1987). Skin manifestations include palmoplantar pustulosis, psoriasis, severe acne and HS (Firinu et al., 2016).

Dysregulation of the ATP receptor $\mathrm{P}_{2} \mathrm{X}_{7}$ in SAPHO PBMCs causes in increased processing of IL- $1 \beta$ suggesting a possible therapeutic approach: $100 \mathrm{mg} /$ day Anakinra treatment in a 47-year-old female resulted in the disappearance of the symptoms within 3 months (Colina et al., 2010). In a short-term open study 6 SAPHO patients received $100 \mathrm{mg}$ /day Anakinra, with clinical response reported in 5/6 patients (Wendling et al., 2012).

Behçet's disease (BD) is a chronic multisystem disease that features vasculitis leading to clinical symptoms comprising bipolar aphtosis (oral and genital), uveitis, polyarthritis and skin lesions including sterile non-follicular pustules on the skin and erythema nodosum (Mazzoccoli et al., 2016). The etiology of $\mathrm{BD}$ is still unclear but there is an association with genetic factors like human leukocyte antigen (HLA)-B51 or the extrinsic 
factor heat shock protein from Streptococcus sanguinis which could activate the innate immune system via TLR signaling (Alpsoy, 2016). Anti-IL-1 $\beta$ therapy is an effective treatment of Behçet's disease. Treatment with Anakinra of nine BD patients refractory to anti-TNF resulted in a response in eight individuals (Cantarini et al., 2015). Treatment of three BD patients with $150 \mathrm{mg}$ Canakinumab every 6-8 weeks resulted in complete remission of all clinical manifestations and relapse was not observed at long-term follow up (Vitale et al., 2014). A recent retrospective study showed that the treatment of patients with Canakinumab or Anakinra for at least 12 months led to complete and sustainable remission of the disease (Emmi et al., 2016) and was also effective for BD-related uveitis (Fabiani et al., 2016).

A phase 3 clinical trial evaluating Gevokizumab for the treatment of patients with BD uveitis was terminated because it did not meet the primary endpoint criteria. However, decreased disease severity was observed in the setting of this trial (ClinicalTrial.gov Identifier: NCT01965145) (Xoma, 2015).

\section{Neutrophilic Dermatoses}

Pyoderma gangrenosum (PG) is a rare non-infectious neutrophilic dermatosis characterized by sterile pustular skin lesions that rapidly evolve into tender skin ulcers with undermined borders of varying size and depth, sometimes exposing underlying tendons or muscles. PG is frequently associated with systemic diseases. Increased expression of IL-1 $\beta$ was found in lesional skin of PG patients compared to healthy skin (Marzano et al., 2014b; Kolios et al., 2015). In an open-label, proof of concept study evaluating the anti-IL-1 $\beta$ monoclonal antibody Gevokizumab, six patients with active ulcers received three subcutaneous injections once every 4 weeks and four out of six patients had a complete clearance of the target ulcer, 1 a partial (90\%) closure of the ulcer and 1 did not respond (ClinicalTrials.gov Identifier: NCT01882504) (Huang et al., 2014, poster). A phase 3 trial of the same drug was prematurely terminated after the company's decision to interrupt clinical development of Gevokizumab. However, preliminary results with 25 patients treated with gevokizumab did not apparently reveal any significant benefit (ClinicalTrials.gov Identifier: NCT02326740 and NCT02315417) (Xoma, 2016). Canakinumab treatment was first reported in a PG patient with concomitant HS. Ulceration disappeared after 4 months and complete remission was achieved after 12 months of treatment (Jaeger et al., 2013). In an open-label study, five steroid-refractory PG patients were treated with Canakinumab once with $150 \mathrm{mg}$ at onset and then optionally at weeks 2 and 8 if response was suboptimal. At the week 16 study endpoint $80 \%$ of the patients showed decreased size of target ulcers and $60 \%$ were in complete remission (ClinicalTrials.gov Identifier: NCT01302795) (Kolios et al., 2015). A case report described complete healing of a PG patient that received a Canakinumab monthly at a $150 \mathrm{mg}$ dose for 3 months (Galimberti et al., 2016). The involvement of IL-1 $\alpha$ in the pathogenesis of PG is currently being investigated in a phase 2 open label study of MABp1 (ClinicalTrials.gov Identifier: NCT01965613) (unpublished data).
Sweet's syndrome (SwS) or acute febrile neutrophilic dermatosis, is a neutrophilic dermatosis with systemic symptoms characterized by fever, tender red cutaneous nodules or papules, occasionally covered with vesicles, pustules or bullae, usually affecting the upper limbs, face and neck. SwS is frequently observed in patients with leukemia or connective tissue diseases. Overexpression of proinflammatory genes including IL-1 $\beta$ is reported in lesional skin of SwS patients (Marzano et al., 2014b; Imhof et al., 2015).

Anakinra (100 mg/day) resulted in symptom resolution within 4 days and subsequent remission for 19 months in one case reported (Delluc et al., 2008). Another case report described disappearance of skin lesions within a month of Anakinra treatment and reappearance of symptoms upon withdrawal (Kluger et al., 2011).

Amicrobial pustulosis of the skin folds (APF) is a rare, chronic cutaneous disease presenting aseptic pustular lesions in cutaneous folds and usually occurring in young women affected by autoimmune diseases such as SLE (Marzano et al., 1996).

Treatment of APF with Anakinra was described in one patient who had increased levels of IL- $1 \alpha$ expression in lesional skin, was refractory to steroid therapy and TNF antagonists. Daily subcutaneous injection of Anakinra for 1 month resulted in clearance of the lesions (Amazan et al., 2014).

\section{Other Diseases with Skin Involvement}

\section{Acne Vulgaris}

Acne vulgaris is a common inflammatory and potentially severe skin disease associated with colonization of the pilo-sebaceous unit by the commensal bacterium $P$. acnes. $P$. acnes is considered to contribute to inflammation in acne and has been shown to activate the NLRP3 inflammasome in human monocytes (Kistowska et al., 2014b; Qin et al., 2014) and in sebocytes (Li et al., 2014). Therefore, IL-1 $\beta$ is thought to play an important role in acne pathogenesis. Gevokizumab was evaluated in a double-blind, randomized, placebo-controlled phase 2 trial for the treatment of inflammatory facial lesions. Patients who received $0.6 \mathrm{mg} / \mathrm{kg}$ Gevokizumab once a month for 3 months showed a significant clinical response associated with reduction of inflammatory acne lesions in comparison to the control group (ClinicalTrial.gov Identifier: NCT01498874) (Xoma, 2013). On the other hand, an open label, phase 2 study testing the anti-IL- $1 \alpha$ antibody MABp1 on 11 patients showed a $36 \%$ decrease in lesion counts (Carrasco et al., 2015).

\section{Malassezia-Associated Skin Diseases}

The fungal genus Malassezia is linked to several inflammatory skin diseases such as seborrheic dermatitis (seborrheic eczema), pityriasis versicolor (tinea versicolor), atopic eczema, psoriasis, Malassezia folliculitis and Onychomycoses (Gaitanis et al., 2012). The etiological agent of pityriasis versicolor, Malassezia was shown to activate the NLRP3 inflammasome via the dectin-1 and Syk signaling cascade, causing the release of IL-1 $\beta$ (Kistowska et al., 2014a). To date, no IL-1 blocker has been evaluated for the treatment of Malassezia-associated skin diseases. 
Psoriasis is an immune-mediated inflammatory disease that affects $2-3 \%$ of the global population. It affects primarily the skin and the joints. Psoriasis vulgaris manifests as red, scaly patches of the skin. In lesions, keratinocytes express IL- $1 \alpha, \mathrm{IL}-1 \beta$, and IL-18 which regulate the expression of genes involved in the pathogenesis of psoriasis including S100A7 and LL-37 (Perera et al., 2012). By binding to cytosolic DNA, LL-37 has been shown to impair the activation of the AIM2 inflammasome, which is highly expressed in psoriatic lesions (Dombrowski et al., 2011). However, LL-37 is able to induce secretion of IL-18 from keratinocytes independently of caspase-1 (Niyonsaba et al., 2005). IL-1 $\alpha$ inhibition for the treatment of plaque psoriasis was investigated in a small size (eight patients), open-label, single-arm trial. $200 \mathrm{mg}$ of MABp1 injected subcutaneously every 3 weeks until evaluation at day 56 showed an average of $13 \%$ decrease of the PASI score (Coleman et al., 2015), which is lower than that obtained with the current approved therapies using anti-TNF, -IL-17A, and -IL-12/IL-23 (Mansouri and Menter, 2015).

Generalized pustular psoriasis (GPP; OMIM \# 614204, \# 602723 ) is a rare, severe form of psoriasis caused by mutations in the IL36RN and CARD14 genes. Treatment of GPP with Anakinra (Viguier et al., 2010) and Gevokizumab (Mansouri et al., 2015) resulted in a reduction in GPP area and severity index.

Moreover, the caspase-1 inhibitor Belnacasan (VX-765) was evaluated in a phase $2 \mathrm{a}$ trial against psoriasis but patients

TABLE 2 | Selected clinical trials targeting IL-1 in inflammatory skin diseases.

\begin{tabular}{|c|c|c|c|c|c|c|}
\hline Syndrome & Drug & CTI & $n$ & $\mathbf{P h}$ & Design & Reference \\
\hline FCAS & Anakinra & NCT00214851 & 8 & 1 & $\mathrm{O}$ & Ross et al., 2008 \\
\hline FCAS/MWS & Rilonacept & NCT00288704 & 47 & 3 & R-B-P, W & Hoffman et al., 2008 \\
\hline CAPS & Canakinumab & NCT00465985 & 35 & 3 & O, R-B-P, W & Lachmann et al., 2009 \\
\hline MWS/CINCA & Canakinumab & NCT00487708 & 34 & 2 & $\mathrm{O}$ & Kuemmerle-Deschner et al., 2011b \\
\hline CINCA & Canakinumab & NCT00770601 & 6 & 3 & $\mathrm{O}$ & Sibley et al., 2015 \\
\hline CAPS & Canakinumab & NCT00991146 & 19 & 3 & $\mathrm{O}$ & Yokota et al., 2016 \\
\hline CAPS & Canakinumab & NCT01213641 & 288 & pr & 0 & Hoffman et al., 2016 \\
\hline FMF & Anakinra & NCT01705756 & 25 & 3 & R-B-P & Ben-Zvi et al., 2017 \\
\hline FMF & Rilonacept & NCT00582907 & 14 & 2 & R-B-AT & Hashkes et al., 2012 \\
\hline FMF & Canakinumab & NCT01148797 & 7 & 2 & $\mathrm{O}$ & Brik et al., 2014 \\
\hline MKD/HIDS & Canakinumab & NCT01303380 & 9 & 2 & o, w & Aróstegui et al., 2015 \\
\hline SchS & Rilonacept & NCT01045772 & 8 & 2 & $\mathrm{O}$ & Krause et al., 2012 \\
\hline SchS & Canakinumab & NCT01276522 & 8 & 2 & $\mathrm{O}$ & de Koning et al., 2013 \\
\hline SchS & Canakinumab & NCT01245127 & 1 & 2 & $\mathrm{O}$ & Vanderschueren and Knockaert, 2013 \\
\hline SchS & Canakinumab & NCT01390350 & 20 & 2 & R-B-P, O & Krause et al., 2017 \\
\hline HS & Anakinra & NCT01558375 & 20 & 2 & R-B-P & Tzanetakou et al., 2016 \\
\hline HS & MABp1 & NCT02643654 & 20 & 2 & R-B-P & Xbiotech, 2017 \\
\hline BD (uveitis) & Gevokizumab & NCT01965145 ${ }^{\dagger}$ & 83 & 3 & R-B-P & Xoma, 2015 \\
\hline PG & Gevokizumab & NCT01882504 & 6 & 2 & 0 & Huang et al., 2014 \\
\hline$P G$ & Gevokizumab & NCT02326740 ${ }^{\dagger}$ & 9 & 3 & R-B-P, O & Xoma, 2016 \\
\hline$P G$ & Gevokizumab & NCT02315417 $7^{\dagger}$ & 16 & 3 & R-B-P, O & Xoma, 2016 \\
\hline sJIA & Canakinumab & NCT00886769 & 84 & 3 & R-B-P & Ruperto et al., 2012 \\
\hline AoSD & Anakinra & NCT01033656 & 22 & 2 & $\mathrm{R}-\mathrm{O}-\mathrm{CD}$ & Nordstrom et al., 2012 \\
\hline
\end{tabular}

CTI, ClinicalTrial.gov Identifier; $n$, number of enrolled individuals; $P$, phase; pr, prospective; $R$, randomized; $O$, open-label; $B$, double-blind; $P$, placebo-controlled; $W$, withdrawal phase; AT, alternating treatment; $C D$, comparator drug; na, not available. In bold: studies having only preliminary or not peer-reviewed results. ${ }^{\dagger}$ Clinical trial was terminated. 
did not respond to this therapy (ClinicalTrial.gov Identifier: NCT00205465) (Vertex, 2011).

Systemic juvenile idiopathic arthritis (sJIA) is a juvenile form of polyarticular arthritis that also presents with systemic symptoms including fever and skin lesions. Standard treatment includes non-steroidal anti-inflammatory drugs, corticosteroids, anti-IL-1 and anti-IL-6 (Cimaz, 2016).

IL-1 blockade with Anakinra, Canakinumab, and Rilonacept has shown positive results in three clinical trials by Quartier et al. (2011) (ClinicalTrials.gov Identifier: NCT00339157), and Ruperto et al. (2012) (ClinicalTrials.gov Identifier: NCT00886769) and Lovell et al. (2013) (ClinicalTrials.gov Identifier: NCT01803321), respectively. These studies are extensively discussed in the review by Giancane et al. (2016) in this issue.

Adult-onset Still's disease (AoSD) is a rare form of inflammatory arthritis that shares symptoms with sJIA but presents during adulthood.

Treatment of AoSD with Anakinra has shown efficacy in several studies (Castaneda et al., 2016). In an open, randomized study involving 22 patients, Anakinra treatment was compared to disease-modifying anti-rheumatic drugs (DMARDs). Patients receiving $\geq 10 \mathrm{mg} /$ day of Anakinra showed a better overall response in comparison to DMARDs (ClinicalTrials.gov Identifier: NCT01033656) (Nordstrom et al., 2012). In another report, three patients with refractory AoSD that were switched from Anakinra to Rilonacept showed prolonged complete remission (Petryna et al., 2012). Treatment of AoSD with Canakinumab was first reported in two patients resistant to Anakinra and resulted in improvement of both systemic symptoms and polyarthritis (Kontzias and Efthimiou, 2012). In another report, a patient receiving $150 \mathrm{mg}$ Canakinumab every 8 weeks showed long-term improvement of systemic symptoms but active arthritis persisted up to 14 months follow-up (Lo Gullo et al., 2014).

Graft-versus-host disease (GvHD) is a severe complication after allogeneic hematopoietic stem cell transplantation (allo-HSCT). Acute GvHD occurs in $35-50 \%$ of transplanted patients and about half of them will eventually develop chronic GvHD (Jacobsohn and Vogelsang, 2007). Skin manifestations include erythema, morbilliform exanthema, and confluent erythroderma, but in the severest forms (Grade IV) widespread skin detachment (Lipsker et al., 2016). First-line treatment for GvHD consists of corticosteroids and calcineurin inhibitors followed by anti-TNF, anti-IL-2 or mTOR inhibitors (Dignan et al., 2012).

The efficacy of Anakinra in the treatment of GvHD was assessed in 1994 in an open-label, phase 1/2 trial of 17 steroid-resistant GvHD patients. Anakinra was continuously administered per infusion for 1 week. In $63 \%$ of the patients, acute GvHD improved by at least one grade (Antin et al., 1994). A second double-blind, placebo-controlled randomized trial on 181 patients investigated the role of IL-1 in the initial T-cell mediated development of the disease by giving Anakinra during conditioning (4 days) and for 10 days after allo-HCT. There was no difference between
IL-1ra- and placebo-treated patients with 61 and 59\% of them, respectively, developing moderate to severe GvHD (Antin et al., 2002).

Recently, in a murine model of acute GvHD, it was demonstrated that conditioning therapy before allo-HCT resulted in NLRP3 activation in the recipient. Microflora translocation and uric acid released by dying cells were able to activate the inflammasome. Inhibition of NLRP3 with glibenclamide, the IL-1 $\beta$ antagonist Anakinra or gene deletion of Nlrp3 or Asc in mice resulted in delayed and reduced mortality (Jankovic et al., 2013).

Similarly, the blockade of IL-18R in mice has been shown to prevent the early phase of GvHD pathogenesis (Li et al., 2015).

\section{CONCLUSION}

Thanks to the discovery of the inflammasome and to major advances in the understanding of biological properties and clinical relevance of IL-1 family members', the use of IL1 antagonists has been quite intensely investigated for the treatment of inflammatory and autoinflammatory diseases (Table 2). The introduction of IL-1 antagonists represents a major breakthrough in the management of several autoinflammatory diseases, including not only cryopyrinopathies but also other inflammatory conditions refractory to standard therapies where neutrophils play an important pathogenic role. Clinical responses to IL- $1 \beta$ antagonists suggest that this cytokine plays a critical role in the pathogenesis of autoinflammatory disorders. Indeed, many studies have demonstrated that there is no loss in therapeutic efficacy when Anakinra is substituted with the IL-1 $\beta$-specific antagonist Canakinumab, suggesting that in comparison to IL$1 \alpha$ and/or IL-18, IL-1 $\beta$ likely plays a predominant role in a substantial number of diseases described in this review.

Due to the rarity of autoinflammatory syndromes, sample size represents a major limitation of clinical studies. Nevertheless, retrospective studies, including online registers such as the $\beta$ confident register for CAPS, that collect data from several reports have definitively helped establishing solid data on the efficacy and safety of IL-1 antagonists for these pathologies.

\section{AUTHOR CONTRIBUTIONS}

GF collected and reviewed the literature, drew the figure and wrote the manuscript. EC and LF gave valuable and professional suggestions and revised the manuscript. All authors approved the final version of the manuscript.

\section{FUNDING}

This work was supported by grants from the Swiss National Science Foundation (31003A-120400 and 310030-156384 to LF). GF is a member of the Microbiology and Immunology Ph.D. program of the Life Science Zurich Graduate School. 


\section{REFERENCES}

Afonina, I. S., Muller, C., Martin, S. J., and Beyaert, R. (2015). Proteolytic processing of interleukin-1 family cytokines: variations on a common theme. Immunity 42, 991-1004. doi: 10.1016/j.immuni.2015.06.003

Aksentijevich, I., Masters, S. L., Ferguson, P. J., Dancey, P., Frenkel, J., van Royen-Kerkhoff, A., et al. (2009). An autoinflammatory disease with deficiency of the interleukin-1-receptor antagonist. N. Engl. J. Med. 360, 2426-2437. doi: 10.1056/NEJMoa0807865

Aksentijevich, I., Nowak, M., Mallah, M., Chae, J. J., Watford, W. T., Hofmann, S. R., et al. (2002). De novo CIAS1 mutations, cytokine activation, and evidence for genetic heterogeneity in patients with neonatal-onset multisystem inflammatory disease (NOMID): a new member of the expanding family of pyrin-associated autoinflammatory diseases. Arthritis Rheum. 46, 3340-3348. doi: 10.1002/art.10688

Alpsoy, E. (2016). Behcet's disease: a comprehensive review with a focus on epidemiology, etiology and clinical features, and management of mucocutaneous lesions. J. Dermatol. 43, 620-632. doi: 10.1111/1346-8138. 13381

Altiok, E., Aksoy, F., Perk, Y., Taylan, F., Kim, P. W., Ilikkan, B., et al. (2012). A novel mutation in the interleukin-1 receptor antagonist associated with intrauterine disease onset. Clin. Immunol. 145, 77-81. doi: 10.1016/j.clim.2012. 08.003

Amazan, E., Ezzedine, K., Mossalayi, M. D., Taieb, A., Boniface, K., and Seneschal, J. (2014). Expression of interleukin-1 alpha in amicrobial pustulosis of the skin folds with complete response to anakinra. J. Am. Acad. Dermatol. 71, e53-e56. doi: 10.1016/j.jaad.2013.12.041

Antin, J. H., Weinstein, H. J., Guinan, E. C., McCarthy, P., Bierer, B. E., Gilliland, D. G., et al. (1994). Recombinant human interleukin-1 receptor antagonist in the treatment of steroid-resistant graft-versus-host disease. Blood 84, 1342-1348.

Antin, J. H., Weisdorf, D., Neuberg, D., Nicklow, R., Clouthier, S., Lee, S. J., et al. (2002). Interleukin-1 blockade does not prevent acute graft-versus-host disease: results of a randomized, double-blind, placebo-controlled trial of interleukin1 receptor antagonist in allogeneic bone marrow transplantation. Blood 100, 3479-3482. doi: 10.1182/blood-2002-03-0985

Aróstegui, J. I., Anton, J., Calvo, I., Robles, A., Speziale, A., Joubert, Y., et al. (2015). Long-term efficacy and safety of Canakinumab in active Hyper-IgD syndrome (HIDS): results from an open-label study. Pediatr. Rheumatol. Online J. 13(Suppl. 1), O58. doi: 10.1186/1546-0096-13-S1-O58

Aróstegui, J. I., Arnal, C., Merino, R., Modesto, C., Antonia Carballo, M., Moreno, P., et al. (2007). NOD2 gene-associated pediatric granulomatous arthritis: clinical diversity, novel and recurrent mutations, and evidence of clinical improvement with interleukin-1 blockade in a Spanish cohort. Arthritis Rheum. 56, 3805-3813. doi: 10.1002/art.22966

Assier, E., Bessis, N., Zagury, J. F., and Boissier, M. C. (2017). IL-1 vaccination is suitable for treating inflammatory diseases. Front. Pharmacol. 8:6. doi: 10.3389/ fphar.2017.00006

Bachetti, T., and Ceccherini, I. (2014). Tumor necrosis factor receptor-associated periodic syndrome as a model linking autophagy and inflammation in protein aggregation diseases. J. Mol. Med. 92, 583-594. doi: 10.1007/s00109-014-1150-5

Beeson, P. B. (1948). Temperature-elevating effect of a substance obtained from polymorphonuclear leucocytes. J. Clin. Invest. 27:524.

Ben-Zvi, I., Kukuy, O., Giat, E., Pras, E., Feld, O., Kivity, S., et al. (2017). Anakinra for colchicine resistant familial Mediterranean fever - A randomized, double blind, placebo-controlled trial. Arthritis Rheumatol. 69, 854-862. doi: 10.1002/ art.39995

Berger, R., Smit, G. P., Schierbeek, H., Bijsterveld, K., and le Coultre, R. (1985). Mevalonic aciduria: an inborn error of cholesterol biosynthesis? Clin. Chim. Acta 152, 219-222. doi: 10.1016/0009-8981(85)90195-0

Bihorel, S., Fiedler-Kelly, J., Ludwig, E., Sloan-Lancaster, J., and Raddad, E. (2014). Population pharmacokinetic modeling of LY2189102 after multiple intravenous and subcutaneous administrations. AAPS J. 16, 1009-1017. doi: 10.1208/s12248-014-9623-6

Blech, M., Peter, D., Fischer, P., Bauer, M. M., Hafner, M., Zeeb, M., et al. (2013). One target-two different binding modes: structural insights into gevokizumab and canakinumab interactions to interleukin-1beta. J. Mol. Biol. 425, 94-111. doi: 10.1016/j.jmb.2012.09.021
Bodar, E. J., Kuijk, L. M., Drenth, J. P., van der Meer, J. W., Simon, A., and Frenkel, J. (2011). On-demand anakinra treatment is effective in mevalonate kinase deficiency. Ann. Rheum. Dis. 70, 2155-2158. doi: 10.1136/ard.2011. 149922

Bodar, E. J., van der Hilst, J. C., Drenth, J. P., van der Meer, J. W., and Simon, A. (2005). Effect of etanercept and anakinra on inflammatory attacks in the hyperIgD syndrome: introducing a vaccination provocation model. Neth. J. Med. 63, 260-264.

Boraschi, D., and Tagliabue, A. (2013). The interleukin-1 receptor family. Semin. Immunol. 25, 394-407. doi: 10.1016/j.smim.2013.10.023

Bossaller, L., Chiang, P. I., Schmidt-Lauber, C., Ganesan, S., Kaiser, W. J., Rathinam, V. A., et al. (2012). Cutting edge: FAS (CD95) mediates noncanonical IL-1beta and IL-18 maturation via caspase- 8 in an RIP3-independent manner. J. Immunol. 189, 5508-5512. doi: 10.4049/jimmunol.1202121

Braddock, M., and Quinn, A. (2004). Targeting IL-1 in inflammatory disease: new opportunities for therapeutic intervention. Nat. Rev. Drug Discov. 3, 330-339. doi: $10.1038 / \mathrm{nrd} 1342$

Braun-Falco, M., Kovnerystyy, O., Lohse, P., and Ruzicka, T. (2012). Pyoderma gangrenosum, acne, and suppurative hidradenitis (PASH)-a new autoinflammatory syndrome distinct from PAPA syndrome. J. Am. Acad. Dermatol. 66, 409-415. doi: 10.1016/j.jaad.2010.12.025

Brenner, M., Ruzicka, T., Plewig, G., Thomas, P., and Herzer, P. (2009). Targeted treatment of pyoderma gangrenosum in PAPA (pyogenic arthritis, pyoderma gangrenosum and acne) syndrome with the recombinant human interleukin-1 receptor antagonist anakinra. Br. J. Dermatol. 161, 1199-1201. doi: 10.1111/j. 1365-2133.2009.09404.x

Brik, R., Butbul-Aviel, Y., Lubin, S., Ben Dayan, E., Rachmilewitz-Minei, T., Tseng, L., et al. (2014). Canakinumab for the treatment of children with colchicine-resistant familial Mediterranean fever: a 6-month open-label, single-arm pilot study. Arthritis Rheumatol. 66, 3241-3243. doi: 10.1002/art. 38777

Brizi, M. G., Galeazzi, M., Lucherini, O. M., Cantarini, L., and Cimaz, R. (2012). Successful treatment of tumor necrosis factor receptor-associated periodic syndrome with canakinumab. Ann. Intern. Med. 156, 907-908. doi: 10.7326/ 0003-4819-156-12-201206190-00027

Bruzzese, V. (2012). Pyoderma gangrenosum, acne conglobata, suppurative hidradenitis, and axial spondyloarthritis: efficacy of anti-tumor necrosis factor alpha therapy. J. Clin. Rheumatol. 18, 413-415. doi: 10.1097/RHU. 0b013e318278b84c

Brydges, S. D., Broderick, L., McGeough, M. D., Pena, C. A., Mueller, J. L., and Hoffman, H. M. (2013). Divergence of IL-1, IL-18, and cell death in NLRP3 inflammasomopathies. J. Clin. Invest. 123, 4695-4705. doi: 10.1172/JCI 71543

Brydges, S. D., Mueller, J. L., McGeough, M. D., Pena, C. A., Misaghi, A., Gandhi, C., et al. (2009). Inflammasome-mediated disease animal models reveal roles for innate but not adaptive immunity. Immunity 30, 875-887. doi: 10.1016/j.immuni.2009.05.005

Burger, D., Chicheportiche, R., Giri, J. G., and Dayer, J. M. (1995). The inhibitory activity of human interleukin-1 receptor antagonist is enhanced by type II interleukin-1 soluble receptor and hindered by type I interleukin-1 soluble receptor. J. Clin. Invest. 96, 38-41. doi: 10.1172/JCI118045

Calderon-Castrat, X., Bancalari-Diaz, D., Roman-Curto, C., Romo-Melgar, A., Amoros-Cerdan, D., Alcaraz-Mas, L. A., et al. (2016). PSTPIP1 gene mutation in a pyoderma gangrenosum, acne and suppurative hidradenitis (PASH) syndrome. Br. J. Dermatol. 175, 194-198. doi: 10.1111/bjd.14383

Calligaris, L., Marchetti, F., Tommasini, A., and Ventura, A. (2008). The efficacy of anakinra in an adolescent with colchicine-resistant familial Mediterranean fever. Eur. J. Pediatr. 167, 695-696. doi: 10.1007/s00431-007-0547-3

Canna, S. W., de Jesus, A. A., Gouni, S., Brooks, S. R., Marrero, B., Liu, Y., et al. (2014). An activating NLRC4 inflammasome mutation causes autoinflammation with recurrent macrophage activation syndrome. Nat. Genet. 46, 1140-1146. doi: 10.1038/ng.3089

Cantarini, L., Vitale, A., Scalini, P., Dinarello, C. A., Rigante, D., Franceschini, R., et al. (2015). Anakinra treatment in drug-resistant Behcet's disease: a case series. Clin. Rheumatol. 34, 1293-1301. doi: 10.1007/s10067-013-2443-8

Carrasco, D., Stecher, M., Lefebvre, G. C., Logan, A. C., and Moy, R. (2015). An open label, phase 2 study of MABp1 monotherapy for the treatment of acne vulgaris and psychiatric comorbidity. J. Drugs Dermatol. 14, 560-564. 
Castaneda, S., Blanco, R., and Gonzalez-Gay, M. A. (2016). Adult-onset Still's disease: advances in the treatment. Best Pract. Res. Clin. Rheumatol. 30, 222-238. doi: 10.1016/j.berh.2016.08.003

Cavelti-Weder, C., Timper, K., Seelig, E., Keller, C., Osranek, M., Lassing, U., et al. (2016). Development of an interleukin-1beta vaccine in patients with type 2 diabetes. Mol. Ther. 24, 1003-1012. doi: 10.1038/mt.2015.227

Chae, J. J., Wood, G., Masters, S. L., Richard, K., Park, G., Smith, B. J., et al. (2006). The B30.2 domain of pyrin, the familial Mediterranean fever protein, interacts directly with caspase-1 to modulate IL-1beta production. Proc. Natl. Acad. Sci. U.S.A. 103, 9982-9987. doi: 10.1073/pnas.0602081103

Chamot, A. M., Benhamou, C. L., Kahn, M. F., Beraneck, L., Kaplan, G., and Prost, A. (1987). Acne-pustulosis-hyperostosis-osteitis syndrome. Results of a national survey. 85 cases. Rev. Rhum. Mal. Osteoartic. 54, 187-196.

Chang, Y. P., Ka, S. M., Hsu, W. H., Chen, A., Chao, L. K., Lin, C. C., et al. (2015). Resveratrol inhibits NLRP3 inflammasome activation by preserving mitochondrial integrity and augmenting autophagy. J. Cell. Physiol. 230, 1567-1579. doi: 10.1002/jcp.24903

Chavarria-Smith, J., Mitchell, P. S., Ho, A. M., Daugherty, M. D., and Vance, R. E. (2016). Functional and evolutionary analyses identify proteolysis as a general mechanism for NLRP1 inflammasome activation. PLoS Pathog. 12:e1006052. doi: 10.1371/journal.ppat.1006052

Chen, C. J., Kono, H., Golenbock, D., Reed, G., Akira, S., and Rock, K. L. (2007). Identification of a key pathway required for the sterile inflammatory response triggered by dying cells. Nat. Med. 13, 851-856. doi: 10.1038/nm1603

Chen, K., Shanmugam, N. K., Pazos, M. A., Hurley, B. P., and Cherayil, B. J. (2016). Commensal bacteria-induced inflammasome activation in mouse and human macrophages is dependent on potassium efflux but does not require phagocytosis or bacterial viability. PLoS ONE 11:e0160937. doi: 10.1371/ journal.pone.0160937

Cimaz, R. (2016). Systemic-onset juvenile idiopathic arthritis. Autoimmun. Rev. 15, 931-934. doi: 10.1016/j.autrev.2016.07.004

Coleman, K. M., Gudjonsson, J. E., and Stecher, M. (2015). Open-label trial of MABp1, a true human monoclonal antibody targeting interleukin 1alpha, for the treatment of psoriasis. JAMA Dermatol. 151, 555-556. doi: 10.1001/ jamadermatol.2014.5391

Colina, M., Pizzirani, C., Khodeir, M., Falzoni, S., Bruschi, M., Trotta, F., et al. (2010). Dysregulation of P2X7 receptor-inflammasome axis in SAPHO syndrome: successful treatment with anakinra. Rheumatology 49, 1416-1418. doi: 10.1093/rheumatology/keq074

Coll, R. C., Robertson, A. A., Chae, J. J., Higgins, S. C., Munoz-Planillo, R., Inserra, M. C., et al. (2015). A small-molecule inhibitor of the NLRP3 inflammasome for the treatment of inflammatory diseases. Nat. Med. 21, 248-255. doi: 10.1038/ nm.3806

de Koning, H. D., Bodar, E. J., Simon, A., van der Hilst, J. C., Netea, M. G., and van der Meer, J. W. (2006). Beneficial response to anakinra and thalidomide in Schnitzler's syndrome. Ann. Rheum. Dis. 65, 542-544. doi: 10.1136/ard.2005. 045245

de Koning, H. D., Schalkwijk, J., van der Meer, J. W., and Simon, A. (2011). Successful canakinumab treatment identifies IL-1beta as a pivotal mediator in Schnitzler syndrome. J. Allergy Clin. Immunol. 128, 1352-1354. doi: 10.1016/j. jaci.2011.05.023

de Koning, H. D., Schalkwijk, J., van der Ven-Jongekrijg, J., Stoffels, M., van der Meer, J. W., and Simon, A. (2013). Sustained efficacy of the monoclonal anti-interleukin-1 beta antibody canakinumab in a 9-month trial in Schnitzler's syndrome. Ann. Rheum. Dis. 72, 1634-1638. doi: 10.1136/annrheumdis-2012202192

Delluc, A., Limal, N., Puechal, X., Frances, C., Piette, J. C., and Cacoub, P. (2008). Efficacy of anakinra, an IL1 receptor antagonist, in refractory Sweet syndrome. Ann. Rheum. Dis. 67, 278-279. doi: 10.1136/ard.2006.068254

Di Paolo, N. C., and Shayakhmetov, D. M. (2016). Interleukin lalpha and the inflammatory process. Nat. Immunol. 17, 906-913. doi: 10.1038/ni.3503

Dierselhuis, M. P., Frenkel, J., Wulffraat, N. M., and Boelens, J. J. (2005). Anakinra for flares of pyogenic arthritis in PAPA syndrome. Rheumatology 44, 406-408. doi: 10.1093/rheumatology/keh479

Dignan, F. L., Clark, A., Amrolia, P., Cornish, J., Jackson, G., Mahendra, P., et al. (2012). Diagnosis and management of acute graft-versus-host disease. Br. J. Haematol. 158, 30-45. doi: 10.1111/j.1365-2141.2012.09129.x
Dinarello, C. A. (1996). Biologic basis for interleukin-1 in disease. Blood 87, 2095-2147.

Dinarello, C. A. (2009). Immunological and inflammatory functions of the interleukin-1 family. Annu. Rev. Immunol. 27, 519-550. doi: 10.1146/annurev. immunol.021908.132612

Dinarello, C. A. (2011). Blocking interleukin-1beta in acute and chronic autoinflammatory diseases. J. Intern. Med. 269, 16-28. doi: 10.1111/j.13652796.2010.02313.x

Dinarello, C. A., Goldin, N. P., and Wolff, S. M. (1974). Demonstration and characterization of two distinct human leukocytic pyrogens. J. Exp. Med. 139, 1369-1381. doi: 10.1084/jem.139.6.1369

Dinarello, C. A., Novick, D., Kim, S., and Kaplanski, G. (2013). Interleukin-18 and IL-18 binding protein. Front. Immunol. 4:289. doi: 10.3389/fimmu.2013.00289

Dinarello, C. A., Renfer, L., and Wolff, S. M. (1977). Human leukocytic pyrogen: purification and development of a radioimmunoassay. Proc. Natl. Acad. Sci. U.S.A. 74, 4624-4627. doi: 10.1073/pnas.74.10.4624

Dombrowski, Y., Peric, M., Koglin, S., Kammerbauer, C., Goss, C., Anz, D., et al. (2011). Cytosolic DNA triggers inflammasome activation in keratinocytes in psoriatic lesions. Sci. Transl. Med. 3:82ra38. doi: 10.1126/scitranslmed.300 2001

Dostert, C., Petrilli, V., Van Bruggen, R., Steele, C., Mossman, B. T., and Tschopp, J. (2008). Innate immune activation through Nalp3 inflammasome sensing of asbestos and silica. Science 320, 674-677. doi: 10.1126/science.1156995

Drewe, E., Powell, R. J., and McDermott, E. M. (2007). Comment on: failure of anti-TNF therapy in TNF receptor 1-associated periodic syndrome (TRAPS). Rheumatology 46, 1865-1866. doi: 10.1093/rheumatology/kem231

Duchatelet, S., Miskinyte, S., Join-Lambert, O., Ungeheuer, M. N., Frances, C., Nassif, A., et al. (2015). First nicastrin mutation in PASH (pyoderma gangrenosum, acne and suppurative hidradenitis) syndrome. Br. J. Dermatol. 173, 610-612. doi: 10.1111/bjd.13668

Duewell, P., Kono, H., Rayner, K. J., Sirois, C. M., Vladimer, G., Bauernfeind, F. G., et al. (2010). NLRP3 inflammasomes are required for atherogenesis and activated by cholesterol crystals. Nature 464, 1357-1361. doi: 10.1038/ nature 08938

Dybowski, F., Sepp, N., Bergerhausen, H. J., and Braun, J. (2008). Successful use of anakinra to treat refractory Schnitzler's syndrome. Clin. Exp. Rheumatol. 26, 354-357.

Emmi, G., Talarico, R., Lopalco, G., Cimaz, R., Cantini, F., Viapiana, O., et al. (2016). Efficacy and safety profile of anti-interleukin-1 treatment in Behcet's disease: a multicenter retrospective study. Clin. Rheumatol. 35, 1281-1286. doi: 10.1007/s10067-015-3004-0

Fabiani, C., Vitale, A., Emmi, G., Lopalco, G., Vannozzi, L., Guerriero, S., et al. (2016). Interleukin (IL)-1 inhibition with anakinra and canakinumab in Behcet's disease-related uveitis: a multicenter retrospective observational study. Clin. Rheumatol. 36, 191-197. doi: 10.1007/s10067-016-3506-4

FDA (2016). FDA Approves Expanded Indications for Ilaris for Three Rare Diseases. Available at: http://www.fda.gov/NewsEvents/Newsroom/ PressAnnouncements/ucm522283.htm

Feldmeyer, L., Keller, M., Niklaus, G., Hohl, D., Werner, S., and Beer, H. D. (2007). The inflammasome mediates UVB-induced activation and secretion of interleukin-1beta by keratinocytes. Curr. Biol. 17, 1140-1145. doi: 10.1016/j. cub.2007.05.074

Feldmeyer, L., Werner, S., French, L. E., and Beer, H. D. (2010). Interleukin-1, inflammasomes and the skin. Eur. J. Cell Biol. 89, 638-644. doi: 10.1016/j.ejcb. 2010.04.008

Fettelschoss, A., Kistowska, M., LeibundGut-Landmann, S., Beer, H. D., Johansen, P., Senti, G., et al. (2011). Inflammasome activation and IL-1beta target IL-1alpha for secretion as opposed to surface expression. Proc. Natl. Acad. Sci. U.S.A. 108, 18055-18060. doi: 10.1073/pnas.1109176108

Firinu, D., Garcia-Larsen, V., Manconi, P. E., and Del Giacco, S. R. (2016). SAPHO syndrome: current developments and approaches to clinical treatment. Curr. Rheumatol. Rep. 18, 35. doi: 10.1007/s11926-016-0583-y

Franchi, L., Warner, N., Viani, K., and Nunez, G. (2009). Function of Nodlike receptors in microbial recognition and host defense. Immunol. Rev. 227, 106-128. doi: 10.1111/j.1600-065X.2008.00734.x

French FMF Consortium (1997). A candidate gene for familial Mediterranean fever. Nat. Genet. 17, 25-31. doi: 10.1038/ng0997-25 
Gaitanis, G., Magiatis, P., Hantschke, M., Bassukas, I. D., and Velegraki, A. (2012). The Malassezia genus in skin and systemic diseases. Clin. Microbiol. Rev. 25, 106-141. doi: 10.1128/CMR.00021-11

Galimberti, R. L., Vacas, A. S., Bollea Garlatti, M. L., and Torre, A. C. (2016). The role of interleukin-1beta in pyoderma gangrenosum. JAAD Case Rep. 2, 366-368. doi: 10.1016/j.jdcr.2016.07.007

Gattorno, M., Obici, L., Cattalini, M., Tormey, V., Abrams, K., Davis, N., et al. (2017). Canakinumab treatment for patients with active recurrent or chronic TNF receptor-associated periodic syndrome (TRAPS): an open-label, phase II study. Ann. Rheum. Dis. 76, 173-178. doi: 10.1136/annrheumdis-2015-209031

Gattorno, M., Pelagatti, M. A., Meini, A., Obici, L., Barcellona, R., Federici, S., et al. (2008). Persistent efficacy of anakinra in patients with tumor necrosis factor receptor-associated periodic syndrome. Arthritis Rheum. 58, 1516-1520. doi: 10.1002/art.23475

Gery, I., Gershon, R. K., and Waksman, B. H. (1972). Potentiation of the T-lymphocyte response to mitogens. I. The responding cell. J. Exp. Med. 136, 128-142. doi: 10.1084/jem.136.1.128

Geusau, A., Mothes-Luksch, N., Nahavandi, H., Pickl, W. F., Wise, C. A., Pourpak, Z., et al. (2013). Identification of a homozygous PSTPIP1 mutation in a patient with a PAPA-like syndrome responding to canakinumab treatment. JAMA Dermatol. 149, 209-215. doi: 10.1001/2013.jamadermatol.717

Giancane, G., Minoia, F., Davi, S., Bracciolini, G., Consolaro, A., and Ravelli, A. (2016). IL-1 inhibition in systemic juvenile idiopathic arthritis. Front. Pharmacol. 7:467. doi: 10.3389/fphar.2016.00467

Goh, A. X., Bertin-Maghit, S., Ping Yeo, S., Ho, A. W., Derks, H., Mortellaro, A., et al. (2014). A novel human anti-interleukin-1beta neutralizing monoclonal antibody showing in vivo efficacy. MAbs 6, 765-773. doi: 10.4161/mabs.28614

Goldbach-Mansky, R. (2011). Current status of understanding the pathogenesis and management of patients with NOMID/CINCA. Curr. Rheumatol. Rep. 13, 123-131. doi: 10.1007/s11926-011-0165-y

Goldbach-Mansky, R., Dailey, N. J., Canna, S. W., Gelabert, A., Jones, J., Rubin, B. I., et al. (2006). Neonatal-onset multisystem inflammatory disease responsive to interleukin-1beta inhibition. N. Engl. J. Med. 355, 581-592. doi: 10.1056/ NEJMoa055137

Goldbach-Mansky, R., Shroff, S. D., Wilson, M., Snyder, C., Plehn, S., Barham, B., et al. (2008). A pilot study to evaluate the safety and efficacy of the longacting interleukin-1 inhibitor rilonacept (interleukin-1 Trap) in patients with familial cold autoinflammatory syndrome. Arthritis Rheum. 58, 2432-2442. doi: 10.1002/art.23620

Greco, E., Aita, A., Galozzi, P., Gava, A., Sfriso, P., Negm, O. H., et al. (2015). The novel S59P mutation in the TNFRSF1A gene identified in an adult onset TNF receptor associated periodic syndrome (TRAPS) constitutively activates NF-kappaB pathway. Arthritis Res. Ther. 17, 93. doi: 10.1186/s13075-0150604-7

Gringhuis, S. I., Kaptein, T. M., Wevers, B. A., Theelen, B., van der Vlist, M., Boekhout, T., et al. (2012). Dectin-1 is an extracellular pathogen sensor for the induction and processing of IL-1beta via a noncanonical caspase- 8 inflammasome. Nat. Immunol. 13, 246-254. doi: 10.1038/ni.2222

Gross, C. J., Mishra, R., Schneider, K. S., Medard, G., Wettmarshausen, J., Dittlein, D. C., et al. (2016). K+ efflux-independent NLRP3 inflammasome activation by small molecules targeting mitochondria. Immunity 45, 761-773. doi: 10.1016/j. immuni.2016.08.010

Gross, O., Yazdi, A. S., Thomas, C. J., Masin, M., Heinz, L. X., Guarda, G., et al. (2012). Inflammasome activators induce interleukin-1alpha secretion via distinct pathways with differential requirement for the protease function of caspase-1. Immunity 36, 388-400. doi: 10.1016/j.immuni.2012.01.018

Gül, A., Ozdogan, H., Erer, B., Ugurlu, S., Kasapcopur, O., Davis, N., et al. (2015). Efficacy and safety of canakinumab in adolescents and adults with colchicineresistant familial Mediterranean fever. Arthritis Res. Ther. 17:243. doi: 10.1186/ s13075-015-0765-4

Haas, D., and Hoffmann, G. F. (2006). Mevalonate kinase deficiencies: from mevalonic aciduria to hyperimmunoglobulinemia D syndrome. Orphanet $J$. Rare Dis. 1:13. doi: 10.1186/1750-1172-1-13

Halle, A., Hornung, V., Petzold, G. C., Stewart, C. R., Monks, B. G., Reinheckel, T., et al. (2008). The NALP3 inflammasome is involved in the innate immune response to amyloid-beta. Nat. Immunol. 9, 857-865. doi: 10.1038/ni.1636

Hara, H., Tsuchiya, K., Kawamura, I., Fang, R., Hernandez-Cuellar, E., Shen, Y., et al. (2013). Phosphorylation of the adaptor ASC acts as a molecular switch that controls the formation of speck-like aggregates and inflammasome activity. Nat. Immunol. 14, 1247-1255. doi: 10.1038/ni.2749

Hashkes, P. J., Spalding, S. J., Giannini, E. H., Huang, B., Johnson, A., Park, G., et al. (2012). Rilonacept for colchicine-resistant or -intolerant familial Mediterranean fever: a randomized trial. Ann. Intern. Med. 157, 533-541. doi: 10.7326/00034819-157-8-201210160-00003

Hawkins, P. N., Lachmann, H. J., and McDermott, M. F. (2003). Interleukin1-receptor antagonist in the Muckle-Wells syndrome. N. Engl. J. Med. 348, 2583-2584. doi: 10.1056/NEJM200306193482523

He, W. T., Wan, H., Hu, L., Chen, P., Wang, X., Huang, Z., et al. (2015). Gasdermin $\mathrm{D}$ is an executor of pyroptosis and required for interleukin-1beta secretion. Cell Res. 25, 1285-1298. doi: 10.1038/cr.2015.139

He, Y., Zeng, M. Y., Yang, D., Motro, B., and Nunez, G. (2016). NEK7 is an essential mediator of NLRP3 activation downstream of potassium efflux. Nature 530, 354-357. doi: 10.1038/nature16959

Hickish, T., Andre, T., Wyrwicz, L., Saunders, M., Sarosiek, T., Kocsis, J., et al. (2017). MABp1 as a novel antibody treatment for advanced colorectal cancer: a randomised, double-blind, placebo-controlled, phase 3 study. Lancet Oncol doi: 10.1016/S1470-2045(17)30006-2 [Epub ahead of print].

Hise, A. G., Tomalka, J., Ganesan, S., Patel, K., Hall, B. A., Brown, G. D., et al. (2009). An essential role for the NLRP3 inflammasome in host defense against the human fungal pathogen Candida albicans. Cell Host Microbe 5, 487-497. doi: 10.1016/j.chom.2009.05.002

Hoffman, H. M., Kuemmerle-Deschner, J. B., Hawkins, P. N., Van der Poll, T., Walker, U. A., Speziale, A., et al. (2016). "Safety and efficacy of long-term canakinumab therapy in patients with CAPS: final results from beta-confident registry," in Proceedings of the 2016 ACR/ARHP Annual Meeting, (Washington, DC: Wiley).

Hoffman, H. M., Mueller, J. L., Broide, D. H., Wanderer, A. A., and Kolodner, R. D. (2001). Mutation of a new gene encoding a putative pyrin-like protein causes familial cold autoinflammatory syndrome and Muckle-Wells syndrome. Nat. Genet. 29, 301-305. doi: 10.1038/ng756

Hoffman, H. M., Rosengren, S., Boyle, D. L., Cho, J. Y., Nayar, J., Mueller, J. L., et al. (2004). Prevention of cold-associated acute inflammation in familial cold autoinflammatory syndrome by interleukin-1 receptor antagonist. Lancet 364 , 1779-1785. doi: 10.1016/S0140-6736(04)17401-1

Hoffman, H. M., Throne, M. L., Amar, N. J., Sebai, M., Kivitz, A. J., Kavanaugh, A., et al. (2008). Efficacy and safety of rilonacept (interleukin-1 Trap) in patients with cryopyrin-associated periodic syndromes: results from two sequential placebo-controlled studies. Arthritis Rheum. 58, 2443-2452. doi: 10.1002/art. 23687

Hong, D. S., Hui, D., Bruera, E., Janku, F., Naing, A., Falchook, G. S., et al. (2014). MABp1, a first-in-class true human antibody targeting interleukin-lalpha in refractory cancers: an open-label, phase 1 dose-escalation and expansion study. Lancet Oncol. 15, 656-666. doi: 10.1016/S1470-2045(14)70155-X

Hornung, V., Bauernfeind, F., Halle, A., Samstad, E. O., Kono, H., Rock, K. L., et al. (2008). Silica crystals and aluminum salts activate the NALP3 inflammasome through phagosomal destabilization. Nat. Immunol. 9, 847-856. doi: 10.1038/ ni. 1631

Hsu, L. C., Ali, S. R., McGillivray, S., Tseng, P. H., Mariathasan, S., Humke, E. W., et al. (2008). A NOD2-NALP1 complex mediates caspase-1-dependent IL-1beta secretion in response to Bacillus anthracis infection and muramyl dipeptide. Proc. Natl. Acad. Sci. U.S.A. 105, 7803-7808. doi: 10.1073/pnas.080272 6105

Hua, K. F., Chou, J. C., Ka, S. M., Tasi, Y. L., Chen, A., Wu, S. H., et al. (2015). Cyclooxygenase-2 regulates NLRP3 inflammasome-derived IL-1beta production. J. Cell. Physiol. 230, 863-874. doi: 10.1002/jcp.24815

Huang, W., Nath, R., Zayed, H., Rubin, P., Moore, A., Snyder, R., et al. (2014). Results of An Open-Label, Proof of Concept Study of Gevokizumab in the Treatment of the Acute, Inflammatory Phase of Pyoderma Gangrenosum. Available at: http://www.xoma.com/content/pipeline/documents/X052170_ AAD2014_Poster_FINAL.pdf [Accessed December 2016].

Hull, K. M., Drewe, E., Aksentijevich, I., Singh, H. K., Wong, K., McDermott, E. M., et al. (2002). The TNF receptor-associated periodic syndrome (TRAPS): emerging concepts of an autoinflammatory disorder. Medicine 81, 349-368. doi: 10.1097/00005792-200209000-00002

Imhof, L., Meier, B., Frei, P., Kamarachev, J., Rogler, G., Kolios, A., et al. (2015). Severe sweet's syndrome with elevated cutaneous interleukin-1beta after 
azathioprine exposure: case report and review of the literature. Dermatology 230, 293-298. doi: 10.1159/000371879

Infevers. (2017). Infevers: An Online Database for Autoinflammatory Mutations. Available at: http://fmf.igh.cnrs.fr/ISSAID/infevers/ [Accessed March 20, 2017].

Ito, M., Shichita, T., Okada, M., Komine, R., Noguchi, Y., Yoshimura, A., et al. (2015). Bruton's tyrosine kinase is essential for NLRP3 inflammasome activation and contributes to ischaemic brain injury. Nat. Commun. 6:7360. doi: $10.1038 /$ ncomms 8360

Ito, S., Hara, Y., and Kubota, T. (2014). CARD8 is a negative regulator for NLRP3 inflammasome, but mutant NLRP3 in cryopyrin-associated periodic syndromes escapes the restriction. Arthritis Res. Ther. 16, R52. doi: 10.1186/ar4483

Jacobsohn, D. A., and Vogelsang, G. B. (2007). Acute graft versus host disease. Orphanet J. Rare Dis. 2:35. doi: 10.1186/1750-1172-2-35

Jaeger, T., Andres, C., Grosber, M., Zirbs, M., Hein, R., Ring, J., et al. (2013). Pyoderma gangrenosum and concomitant hidradenitis suppurativa-rapid response to canakinumab (anti-IL-1beta). Eur. J. Dermatol. 23, 408-410. doi: 10.1684/ejd.2013.2018

Jankovic, D., Ganesan, J., Bscheider, M., Stickel, N., Weber, F. C., Guarda, G., et al. (2013). The Nlrp3 inflammasome regulates acute graft-versus-host disease. J. Exp. Med. 210, 1899-1910. doi: 10.1084/jem.20130084

Jeru, I., Cochet, E., Duquesnoy, P., Hentgen, V., Copin, B., Mitjavila-Garcia, M. T., et al. (2014). Brief report: involvement of TNFRSF11A molecular defects in autoinflammatory disorders. Arthritis Rheumatol. 66, 2621-2627. doi: 10.1002/ art. 38727

Jeru, I., Duquesnoy, P., Fernandes-Alnemri, T., Cochet, E., Yu, J. W., Lackmy-PortLis, M., et al. (2008). Mutations in NALP12 cause hereditary periodic fever syndromes. Proc. Natl. Acad. Sci. U.S.A. 105, 1614-1619. doi: 10.1073/pnas. 0708616105

Jeru, I., Papin, S., L'Hoste, S., Duquesnoy, P., Cazeneuve, C., Camonis, J., et al. (2005). Interaction of pyrin with 14.3 .3 in an isoform-specific and phosphorylation-dependent manner regulates its translocation to the nucleus. Arthritis Rheum. 52, 1848-1857. doi: 10.1002/art.21050

Jesus, A. A., and Goldbach-Mansky, R. (2014). IL-1 blockade in autoinflammatory syndromes. Annu. Rev. Med. 65, 223-244. doi: 10.1146/annurev-med-061512150641

Jin, Y., Mailloux, C. M., Gowan, K., Riccardi, S. L., LaBerge, G., Bennett, D. C., et al. (2007). NALP1 in vitiligo-associated multiple autoimmune disease. N. Engl. J. Med. 356, 1216-1225. doi: 10.1056/NEJMoa061592

Kailasan Vanaja, S., Rathinam, V. A., Atianand, M. K., Kalantari, P., Skehan, B., Fitzgerald, K. A., et al. (2014). Bacterial RNA:DNA hybrids are activators of the NLRP3 inflammasome. Proc. Natl. Acad. Sci. U.S.A. 111, 7765-7770. doi: 10.1073/pnas.1400075111

Kanameishi, S., Nakamizo, S., Endo, Y., Fujisawa, A., Dainichi, T., Tanaka, T., et al. (2016). High level of serum human interleukin-18 in a patient with pyogenic arthritis, pyoderma gangrenosum and acne syndrome. J. Eur. Acad. Dermatol. Venereol. 31, e115-e116. doi: 10.1111/jdv.13856

Kayagaki, N., Stowe, I. B., Lee, B. L., O’Rourke, K., Anderson, K., Warming, S., et al. (2015). Caspase-11 cleaves gasdermin D for non-canonical inflammasome signalling. Nature 526, 666-671. doi: 10.1038/nature15541

Kayagaki, N., Warming, S., Lamkanfi, M., Vande Walle, L., Louie, S., Dong, J., et al. (2011). Non-canonical inflammasome activation targets caspase-11. Nature 479, 117-121. doi: 10.1038/nature 10558

Keller, M., Ruegg, A., Werner, S., and Beer, H. D. (2008). Active caspase-1 is a regulator of unconventional protein secretion. Cell 132, 818-831. doi: 10.1016/ j.cell.2007.12.040

Kim, B., Lee, Y., Kim, E., Kwak, A., Ryoo, S., Bae, S. H., et al. (2013). The interleukin-1alpha precursor is biologically active and is likely a key alarmin in the IL-1 family of cytokines. Front. Immunol. 4:391. doi: 10.3389/fimmu.2013. 00391

Kistowska, M., Fenini, G., Jankovic, D., Feldmeyer, L., Kerl, K., Bosshard, P., et al. (2014a). Malassezia yeasts activate the NLRP3 inflammasome in antigenpresenting cells via Syk-kinase signalling. Exp. Dermatol. 23, 884-889. doi: 10.1111/exd.12552

Kistowska, M., Gehrke, S., Jankovic, D., Kerl, K., Fettelschoss, A., Feldmeyer, L., et al. (2014b). IL-1beta drives inflammatory responses to propionibacterium acnes in vitro and in vivo. J. Invest. Dermatol. 134, 677-685. doi: 10.1038/jid. 2013.438
Kitamura, A., Sasaki, Y., Abe, T., Kano, H., and Yasutomo, K. (2014). An inherited mutation in NLRC4 causes autoinflammation in human and mice. J. Exp. Med. 211, 2385-2396. doi: 10.1084/jem.20141091

Kluger, N., Gil-Bistes, D., Guillot, B., and Bessis, D. (2011). Efficacy of antiinterleukin-1 receptor antagonist anakinra (Kineret(R)) in a case of refractory Sweet's syndrome. Dermatology 222, 123-127. doi: 10.1159/000326112

Kolios, A. G., Maul, J. T., Meier, B., Kerl, K., Traidl-Hoffmann, C., Hertl, M., et al. (2015). Canakinumab in adults with steroid-refractory pyoderma gangrenosum. Br. J. Dermatol. 173, 1216-1223. doi: 10.1111/bjd.14037

Kong, F., Ye, B., Cao, J., Cai, X., Lin, L., Huang, S., et al. (2016). Curcumin represses NLRP3 inflammasome activation via TLR4/MyD88/NF-kappaB and P2X7R signaling in PMA-induced macrophages. Front. Pharmacol. 7:369. doi: 10.3389/fphar.2016.00369

Kontzias, A., and Efthimiou, P. (2012). The use of Canakinumab, a novel IL-1beta long-acting inhibitor, in refractory adult-onset Still's disease. Semin. Arthritis Rheum. 42, 201-205. doi: 10.1016/j.semarthrit.2012.03.004

Krause, K., Tsianakas, A., Wagner, N., Fischer, J., Weller, K., Metz, M., et al. (2017). Efficacy and safety of canakinumab in Schnitzler syndrome: a multicenter randomized placebo-controlled study. J. Allergy Clin. Immunol. 139, 1311-1320. doi: 10.1016/j.jaci.2016.07.041

Krause, K., Weller, K., Stefaniak, R., Wittkowski, H., Altrichter, S., Siebenhaar, F., et al. (2012). Efficacy and safety of the interleukin-1 antagonist rilonacept in Schnitzler syndrome: an open-label study. Allergy 67, 943-950. doi: 10.1111/j. 1398-9995.2012.02843.x

Kuemmerle-Deschner, J. B., Hachulla, E., Cartwright, R., Hawkins, P. N., Tran, T. A., Bader-Meunier, B., et al. (2011a). Two-year results from an open-label, multicentre, phase III study evaluating the safety and efficacy of canakinumab in patients with cryopyrin-associated periodic syndrome across different severity phenotypes. Ann. Rheum. Dis. 70, 2095-2102. doi: 10.1136/ard.2011.152728

Kuemmerle-Deschner, J. B., Ramos, E., Blank, N., Roesler, J., Felix, S. D., Jung, T., et al. (2011b). Canakinumab (ACZ885, a fully human IgG1 anti-IL-1beta mAb) induces sustained remission in pediatric patients with cryopyrin-associated periodic syndrome (CAPS). Arthritis Res. Ther. 13, R34. doi: 10.1186/ar3266

Kurzen, H., Kurokawa, I., Jemec, G. B., Emtestam, L., Sellheyer, K., GiamarellosBourboulis, E. J., et al. (2008). What causes hidradenitis suppurativa? Exp. Dermatol. 17, 455-456; discussion 457-472. doi: 10.1111/j.1600-0625.2008. 00712_1.x

Lachmann, H. J., Kone-Paut, I., Kuemmerle-Deschner, J. B., Leslie, K. S., Hachulla, E., Quartier, P., et al. (2009). Use of canakinumab in the cryopyrinassociated periodic syndrome. N. Engl. J. Med. 360, 2416-2425. doi: 10.1056/ NEJMoa0810787

Lamkanfi, M., Mueller, J. L., Vitari, A. C., Misaghi, S., Fedorova, A., Deshayes, K., et al. (2009). Glyburide inhibits the Cryopyrin/Nalp3 inflammasome. J. Cell Biol. 187, 61-70. doi: 10.1083/jcb.200903124

Laskari, K., Boura, P., Dalekos, G. N., Garyfallos, A., Karokis, D., Pikazis, D., et al. (2017). Longterm beneficial effect of canakinumab in colchicine-resistant familial mediterranean fever. J. Rheumatol. 44, 102-109. doi: 10.3899/jrheum. 160518

Lee, G. S., Subramanian, N., Kim, A. I., Aksentijevich, I., Goldbach-Mansky, R., Sacks, D. B., et al. (2012). The calcium-sensing receptor regulates the NLRP3 inflammasome through Ca2+ and cAMP. Nature 492, 123-127. doi: 10.1038/ nature 11588

Lee, J. K., Kim, S. H., Lewis, E. C., Azam, T., Reznikov, L. L., and Dinarello, C. A. (2004). Differences in signaling pathways by IL-1beta and IL-18. Proc. Natl. Acad. Sci. U.S.A. 101, 8815-8820. doi: 10.1073/pnas.0402800101

Leifer, C. A., and Medvedev, A. E. (2016). Molecular mechanisms of regulation of Toll-like receptor signaling. J. Leukoc. Biol. 100, 927-941. doi: 10.1189/jlb. 2MR0316-117RR

Leslie, K. S., Tripathi, S. V., Nguyen, T. V., Pauli, M., and Rosenblum, M. D. (2014). An open-label study of anakinra for the treatment of moderate to severe hidradenitis suppurativa. J. Am. Acad. Dermatol. 70, 243-251. doi: 10.1016/j. jaad.2013.09.044

Leuenberger, M., Berner, J., Di Lucca, J., Fischer, L., Kaparos, N., Conrad, C., et al. (2016). PASS syndrome: an IL-1-driven autoinflammatory disease. Dermatology 232, 254-258. doi: 10.1159/000443648

Li, X., Zhang, C., Chen, W., Pan, B., Kong, F., Zheng, K., et al. (2015). Protective effect of neutralizing anti-IL-18alpha monoclonal antibody on a mouse model 
of acute graft-versus-host disease. Oncol. Rep. 34, 2031-2039. doi: 10.3892/or. 2015.4176

Li, Z. J., Choi, D. K., Sohn, K. C., Seo, M. S., Lee, H. E., Lee, Y., et al. (2014). Propionibacterium acnes activates the NLRP3 inflammasome in human sebocytes. J. Invest. Dermatol. 134, 2747-2756. doi: 10.1038/jid.2014.221

Lima, A. L., Karl, I., Giner, T., Poppe, H., Schmidt, M., Presser, D., et al. (2016). Keratinocytes and neutrophils are important sources of proinflammatory molecules in hidradenitis suppurativa. Br. J. Dermatol. 174, 514-521. doi: 10.1111/bjd.14214

Lindor, N. M., Arsenault, T. M., Solomon, H., Seidman, C. E., and McEvoy, M. T. (1997). A new autosomal dominant disorder of pyogenic sterile arthritis, pyoderma gangrenosum, and acne: PAPA syndrome. Mayo Clin. Proc. 72, 611-615. doi: 10.1016/S0025-6196(11)63565-9

Lipsker, D., Grattan, C. E. H., and Lovell, C. R. (2016). "Autoinflammatory diseases presenting in the skin," in Rook's Textbook of Dermatology, eds C. E. M. Griffiths, J. Barker, T. Bleiker, R. Chalmers, and D. Creamer (Hoboken, NJ: John Wiley \& Sons, Ltd).

Lo Gullo, A., Caruso, A., Pipitone, N., Macchioni, P., Pazzola, G., and Salvarani, C. (2014). Canakinumab in a case of adult onset still's disease: efficacy only on systemic manifestations. Joint Bone Spine 81, 376-377. doi: 10.1016/j.jbspin. 2013.12.011

Lovell, D. J., Bowyer, S. L., and Solinger, A. M. (2005). Interleukin-1 blockade by anakinra improves clinical symptoms in patients with neonatalonset multisystem inflammatory disease. Arthritis Rheum. 52, 1283-1286. doi: 10.1002/art.20953

Lovell, D. J., Giannini, E. H., Reiff, A. O., Kimura, Y., Li, S., Hashkes, P. J., et al. (2013). Long-term safety and efficacy of rilonacept in patients with systemic juvenile idiopathic arthritis. Arthritis Rheum. 65, 2486-2496. doi: 10.1002/art. 38042

Lupfer, C., and Kanneganti, T. D. (2013). Unsolved mysteries in NLR biology. Front. Immunol. 4:285. doi: 10.3389/fimmu.2013.00285

Maekawa, S., Ohto, U., Shibata, T., Miyake, K., and Shimizu, T. (2016). Crystal structure of NOD2 and its implications in human disease. Nat. Commun. 7:11813. doi: $10.1038 /$ ncomms11813

Man, S. M., and Kanneganti, T. D. (2016). Converging roles of caspases in inflammasome activation, cell death and innate immunity. Nat. Rev. Immunol. 16, 7-21. doi: 10.1038/nri.2015.7

Mandey, S. H., Kuijk, L. M., Frenkel, J., and Waterham, H. R. (2006). A role for geranylgeranylation in interleukin-1beta secretion. Arthritis Rheum. 54, 3690-3695. doi: 10.1002/art.22194

Mansouri, B., and Menter, A. (2015). Reporting of MABp1 for the treatment of psoriasis. JAMA Dermatol. 151, 1143-1144. doi: 10.1001/jamadermatol.2015. 1684

Mansouri, B., Richards, L., and Menter, A. (2015). Treatment of two patients with generalized pustular psoriasis with the interleukin-1beta inhibitor gevokizumab. Br. J. Dermatol. 173, 239-241. doi: 10.1111/bjd.13614

Mariathasan, S., Newton, K., Monack, D. M., Vucic, D., French, D. M., Lee, W. P., et al. (2004). Differential activation of the inflammasome by caspase-1 adaptors ASC and Ipaf. Nature 430, 213-218. doi: 10.1038/nature02664

Mariathasan, S., Weiss, D. S., Newton, K., McBride, J., O'Rourke, K., RooseGirma, M., et al. (2006). Cryopyrin activates the inflammasome in response to toxins and ATP. Nature 440, 228-232. doi: 10.1038/nature04515

Martinon, F., Burns, K., and Tschopp, J. (2002). The inflammasome: a molecular platform triggering activation of inflammatory caspases and processing of proIL-beta. Mol. Cell. 10, 417-426. doi: 10.1016/S1097-2765(02)00599-3

Martinon, F., Petrilli, V., Mayor, A., Tardivel, A., and Tschopp, J. (2006). Goutassociated uric acid crystals activate the NALP3 inflammasome. Nature 440, 237-241. doi: 10.1038/nature04516

Marzano, A. V., Capsoni, F., Berti, E., Gasparini, G., Bottelli, S., and Caputo, R. (1996). Amicrobial pustular dermatosis of cutaneous folds associated with autoimmune disorders: a new entity? Dermatology 193, 88-93.

Marzano, A. V., Ceccherini, I., Gattorno, M., Fanoni, D., Caroli, F., Rusmini, M., et al. (2014a). Association of pyoderma gangrenosum, acne, and suppurative hidradenitis (PASH) shares genetic and cytokine profiles with other autoinflammatory diseases. Medicine 93:e187. doi: 10.1097/MD.0000000000000187

Marzano, A. V., Fanoni, D., Antiga, E., Quaglino, P., Caproni, M., Crosti, C., et al. (2014b). Expression of cytokines, chemokines and other effector molecules in two prototypic autoinflammatory skin diseases, pyoderma gangrenosum and Sweet's syndrome. Clin. Exp. Immunol. 178, 48-56. doi: 10.1111/cei.12394

Marzano, A. V., Trevisan, V., Gattorno, M., Ceccherini, I., De Simone, C., and Crosti, C. (2013). Pyogenic arthritis, pyoderma gangrenosum, acne, and hidradenitis suppurativa (PAPASH): a new autoinflammatory syndrome associated with a novel mutation of the PSTPIP1 gene. JAMA Dermatol. 149, 762-764. doi: 10.1001/jamadermatol.2013.2907

Masters, S. L. (2013). Specific inflammasomes in complex diseases. Clin. Immunol. 147, 223-228. doi: 10.1016/j.clim.2012.12.006

Masters, S. L., Lagou, V., Jeru, I., Baker, P. J., Van Eyck, L., Parry, D. A., et al. (2016). Familial autoinflammation with neutrophilic dermatosis reveals a regulatory mechanism of pyrin activation. Sci. Transl. Med. 8:332ra345. doi: 10.1126/ scitranslmed.aaf 1471

Mazzoccoli, G., Matarangolo, A., Rubino, R., Inglese, M., and De Cata, A. (2016). Behcet syndrome: from pathogenesis to novel therapies. Clin. Exp. Med. 16, 1-12. doi: $10.1007 / \mathrm{s} 10238-014-0328-\mathrm{z}$

McDermott, M. F., Aksentijevich, I., Galon, J., McDermott, E. M., Ogunkolade, B. W., Centola, M., et al. (1999). Germline mutations in the extracellular domains of the $55 \mathrm{kDa}$ TNF receptor, TNFR1, define a family of dominantly inherited autoinflammatory syndromes. Cell 97, 133-144. doi: 10.1016/S00928674(00)80721-7

McKie, E. A., Reid, J. L., Mistry, P. C., DeWall, S. L., Abberley, L., Ambery, P. D., et al. (2016). A study to investigate the efficacy and safety of an anti-interleukin18 monoclonal antibody in the treatment of type 2 diabetes mellitus. PLoS ONE 11:e0150018. doi: 10.1371/journal.pone.0150018

Meixenberger, K., Pache, F., Eitel, J., Schmeck, B., Hippenstiel, S., Slevogt, H., et al. (2010). Listeria monocytogenes-infected human peripheral blood mononuclear cells produce IL-1beta, depending on listeriolysin O and NLRP3. J. Immunol. 184, 922-930. doi: 10.4049/jimmunol.0901346

Menis, D., Maronas-Jimenez, L., Delgado-Marquez, A. M., Postigo-Llorente, C., and Vanaclocha-Sebastian, F. (2015). Two cases of severe hidradenitis suppurativa with failure of anakinra therapy. Br. J. Dermatol. 172, 810-811. doi: 10.1111/bjd.13292

Miao, E. A., Mao, D. P., Yudkovsky, N., Bonneau, R., Lorang, C. G., Warren, S. E., et al. (2010). Innate immune detection of the type III secretion apparatus through the NLRC4 inflammasome. Proc. Natl. Acad. Sci. U.S.A. 107, 3076-3080. doi: 10.1073/pnas.0913087107

Miceli-Richard, C., Lesage, S., Rybojad, M., Prieur, A. M., Manouvrier-Hanu, S., Hafner, R., et al. (2001). CARD15 mutations in Blau syndrome. Nat. Genet. 29, 19-20. doi: 10.1038/ng720

Munoz-Planillo, R., Franchi, L., Miller, L. S., and Nunez, G. (2009). A critical role for hemolysins and bacterial lipoproteins in Staphylococcus aureusinduced activation of the Nlrp3 inflammasome. J. Immunol. 183, 3942-3948. doi: 10.4049/jimmunol.0900729

Munoz-Planillo, R., Kuffa, P., Martinez-Colon, G., Smith, B. L., Rajendiran, T. M., and Nunez, G. (2013). K(+) efflux is the common trigger of NLRP3 inflammasome activation by bacterial toxins and particulate matter. Immunity 38, 1142-1153. doi: 10.1016/j.immuni.2013.05.016

Murakami, T., Ockinger, J., Yu, J., Byles, V., McColl, A., Hofer, A. M., et al. (2012). Critical role for calcium mobilization in activation of the NLRP3 inflammasome. Proc. Natl. Acad. Sci. U.S.A. 109, 11282-11287. doi: 10.1073/ pnas. 1117765109

Muruve, D. A., Petrilli, V., Zaiss, A. K., White, L. R., Clark, S. A., Ross, P. J., et al. (2008). The inflammasome recognizes cytosolic microbial and host DNA and triggers an innate immune response. Nature 452, 103-107. doi: 10.1038/ nature 06664

Nakamura, K., Okamura, H., Nagata, K., Komatsu, T., and Tamura, T. (1993). Purification of a factor which provides a costimulatory signal for gamma interferon production. Infect. Immun. 61, 64-70.

Nakamura, K., Okamura, H., Wada, M., Nagata, K., and Tamura, T. (1989). Endotoxin-induced serum factor that stimulates gamma interferon production. Infect. Immun. 57, 590-595.

Navarini, A. A., Satoh, T. K., and French, L. E. (2016). Neutrophilic dermatoses and autoinflammatory diseases with skin involvement-innate immune disorders. Semin. Immunopathol. 38, 45-56. doi: 10.1007/s00281-015-0 549-6

Neal, D. C. C., Almeida de Jesus, A., Huang, Y., Liu, Y., Goldbach-Mansky, R., and Montealegre, G. (2014). "Safety and efficacy of rilonacept in patients with 
deficiency of interleukin-1 receptor antagonist (DIRA)," in Proceedings of the 2014 ACR/ARHP Annual Meeting, (Boston, MA: Wiley).

Niyonsaba, F., Ushio, H., Nagaoka, I., Okumura, K., and Ogawa, H. (2005). The human beta-defensins $(-1,-2,-3,-4)$ and cathelicidin LL-37 induce IL-18 secretion through p38 and ERK MAPK activation in primary human keratinocytes. J. Immunol. 175, 1776-1784. doi: 10.4049/jimmunol.175.3.1776

Nordstrom, D., Knight, A., Luukkainen, R., van Vollenhoven, R., Rantalaiho, V., Kajalainen, A., et al. (2012). Beneficial effect of interleukin 1 inhibition with anakinra in adult-onset Still's disease. An open, randomized, multicenter study. J. Rheumatol. 39, 2008-2011. doi: 10.3899/jrheum.111549

Okada, M., Matsuzawa, A., Yoshimura, A., and Ichijo, H. (2014). The lysosome rupture-activated TAK1-JNK pathway regulates NLRP3 inflammasome activation. J. Biol. Chem. 289, 32926-32936. doi: 10.1074/jbc.M114.579961

Park, Y. H., Wood, G., Kastner, D. L., and Chae, J. J. (2016). Pyrin inflammasome activation and RhoA signaling in the autoinflammatory diseases FMF and HIDS. Nat. Immunol. 17, 914-921. doi: 10.1038/ni.3457

Perera, G. K., Di Meglio, P., and Nestle, F. O. (2012). Psoriasis. Annu. Rev. Pathol. 7, 385-422. doi: 10.1146/annurev-pathol-011811-132448

Petrilli, V., Papin, S., Dostert, C., Mayor, A., Martinon, F., and Tschopp, J. (2007). Activation of the NALP3 inflammasome is triggered by low intracellular potassium concentration. Cell Death Differ. 14, 1583-1589. doi: 10.1038/sj.cdd. 4402195

Petryna, O., Cush, J. J., and Efthimiou, P. (2012). IL-1 Trap rilonacept in refractory adult onset Still's disease. Ann. Rheum. Dis. 71, 2056-2057. doi: 10.1136/ annrheumdis-2012-201409

Pink, A. E., Simpson, M. A., Desai, N., Dafou, D., Hills, A., Mortimer, P., et al. (2012). Mutations in the gamma-secretase genes NCSTN, PSENEN, and PSEN1 underlie rare forms of hidradenitis suppurativa (acne inversa). J. Invest. Dermatol. 132, 2459-2461. doi: 10.1038/jid.2012.162

Primiano, M. J., Lefker, B. A., Bowman, M. R., Bree, A. G., Hubeau, C., Bonin, P. D., et al. (2016). Efficacy and pharmacology of the NLRP3 inflammasome inhibitor CP-456,773 (CRID3) in murine models of dermal and pulmonary inflammation. J. Immunol. 197, 2421-2433. doi: 10.4049/jimmunol.1600035

Qin, M., Pirouz, A., Kim, M. H., Krutzik, S. R., Garban, H. J., and Kim, J. (2014). Propionibacterium acnes induces IL-1beta secretion via the NLRP3 inflammasome in human monocytes. J. Invest. Dermatol. 134, 381-388. doi: 10.1038/jid.2013.309

Qu, Y., Misaghi, S., Izrael-Tomasevic, A., Newton, K., Gilmour, L. L., Lamkanfi, M., et al. (2012). Phosphorylation of NLRC4 is critical for inflammasome activation. Nature 490, 539-542. doi: 10.1038/nature11429

Qu, Y., Misaghi, S., Newton, K., Maltzman, A., Izrael-Tomasevic, A., Arnott, D., et al. (2016). NLRP3 recruitment by NLRC4 during Salmonella infection. J. Exp. Med. 213, 877-885. doi: 10.1084/jem.20132234

Quartier, P., Allantaz, F., Cimaz, R., Pillet, P., Messiaen, C., Bardin, C., et al. (2011). A multicentre, randomised, double-blind, placebo-controlled trial with the interleukin-1 receptor antagonist anakinra in patients with systemic-onset juvenile idiopathic arthritis (ANAJIS trial). Ann. Rheum. Dis. 70, 747-754. doi: $10.1136 /$ ard.2010.134254

Reddy, S., Jia, S., Geoffrey, R., Lorier, R., Suchi, M., Broeckel, U., et al. (2009). An autoinflammatory disease due to homozygous deletion of the IL1RN locus. N. Engl. J. Med. 360, 2438-2444. doi: 10.1056/NEJMoa0809568

Reikine, S., Nguyen, J. B., and Modis, Y. (2014). Pattern recognition and signaling mechanisms of RIG-I and MDA5. Front. Immunol. 5:342. doi: 10.3389/fimmu. 2014.00342

Romberg, N., Al Moussawi, K., Nelson-Williams, C., Stiegler, A. L., Loring, E., Choi, M., et al. (2014). Mutation of NLRC4 causes a syndrome of enterocolitis and autoinflammation. Nat. Genet. 46, 1135-1139. doi: 10.1038/ng. 3066

Rosenwasser, L. J., Dinarello, C. A., and Rosenthal, A. S. (1979). Adherent cell function in murine T-lymphocyte antigen recognition. IV. Enhancement of murine T-cell antigen recognition by human leukocytic pyrogen. J. Exp. Med. 150, 709-714. doi: 10.1084/jem.150.3.709

Ross, J. B., Finlayson, L. A., Klotz, P. J., Langley, R. G., Gaudet, R., Thompson, K., et al. (2008). Use of anakinra (Kineret) in the treatment of familial cold autoinflammatory syndrome with a 16-month follow-up. J. Cutan. Med. Surg. $12,8-16$.

Ruperto, N., Brunner, H. I., Quartier, P., Constantin, T., Wulffraat, N., Horneff, G., et al. (2012). Two randomized trials of canakinumab in systemic juvenile idiopathic arthritis. N. Engl. J. Med. 367, 2396-2406. doi: 10.1056/ NEJMoa1205099

Russo, V., and Alikhan, A. (2016). Failure of anakinra in a case of severe hidradenitis suppurativa. J. Drugs Dermatol. 15, 772-774.

Saraceno, R., Babino, G., Chiricozzi, A., Zangrilli, A., and Chimenti, S. (2015). PSAPASH: a new syndrome associated with hidradenitis suppurativa with response to tumor necrosis factor inhibition. J. Am. Acad. Dermatol. 72, e42-e44. doi: 10.1016/j.jaad.2014.10.002

Schnellbacher, C., Ciocca, G., Menendez, R., Aksentijevich, I., GoldbachMansky, R., Duarte, A. M., et al. (2013). Deficiency of interleukin-1 receptor antagonist responsive to anakinra. Pediatr. Dermatol. 30, 758-760. doi: 10.1111/ j.1525-1470.2012.01725.x

Schroder, K., and Tschopp, J. (2010). The inflammasomes. Cell 140, 821-832. doi: $10.1016 /$ j.cell.2010.01.040

Shi, H., Wang, Y., Li, X., Zhan, X., Tang, M., Fina, M., et al. (2016). NLRP3 activation and mitosis are mutually exclusive events coordinated by NEK7, a new inflammasome component. Nat. Immunol. 17, 250-258. doi: 10.1038/ni. 3333

Shi, J., Zhao, Y., Wang, K., Shi, X., Wang, Y., Huang, H., et al. (2015). Cleavage of GSDMD by inflammatory caspases determines pyroptotic cell death. Nature 526, 660-665. doi: 10.1038/nature15514

Shi, J., Zhao, Y., Wang, Y., Gao, W., Ding, J., Li, P., et al. (2014). Inflammatory caspases are innate immune receptors for intracellular LPS. Nature 514, 187-192. doi: 10.1038/nature13683

Shimada, K., Crother, T. R., Karlin, J., Dagvadorj, J., Chiba, N., Chen, S., et al. (2012). Oxidized mitochondrial DNA activates the NLRP3 inflammasome during apoptosis. Immunity 36, 401-414. doi: 10.1016/j.immuni.2012.01.009

Shoham, N. G., Centola, M., Mansfield, E., Hull, K. M., Wood, G., Wise, C. A., et al. (2003). Pyrin binds the PSTPIP1/CD2BP1 protein, defining familial Mediterranean fever and PAPA syndrome as disorders in the same pathway. Proc. Natl. Acad. Sci. U.S.A. 100, 13501-13506. doi: 10.1073/pnas.2135380100

Sibley, C. H., Chioato, A., Felix, S., Colin, L., Chakraborty, A., Plass, N., et al. (2015). A 24-month open-label study of canakinumab in neonatal-onset multisystem inflammatory disease. Ann. Rheum. Dis. 74, 1714-1719. doi: 10. 1136/annrheumdis-2013-204877

Siegmund, B., Fantuzzi, G., Rieder, F., Gamboni-Robertson, F., Lehr, H. A., Hartmann, G., et al. (2001). Neutralization of interleukin-18 reduces severity in murine colitis and intestinal IFN-gamma and TNF-alpha production. Am. J. Physiol. Regul. Integr. Comp. Physiol. 281, R1264-R1273.

Simon, A., Bodar, E. J., van der Hilst, J. C., van der Meer, J. W., Fiselier, T. J., Cuppen, M. P., et al. (2004). Beneficial response to interleukin 1 receptor antagonist in traps. Am. J. Med. 117, 208-210. doi: 10.1016/j.amjmed.2004. 02.039

Simonini, G., Xu, Z., Caputo, R., De Libero, C., Pagnini, I., Pascual, V., et al. (2013). Clinical and transcriptional response to the long-acting interleukin-1 blocker canakinumab in Blau syndrome-related uveitis. Arthritis Rheum. 65, 513-518. doi: 10.1002/art.37776

Sivakumar, P. V., Westrich, G. M., Kanaly, S., Garka, K., Born, T. L., Derry, J. M., et al. (2002). Interleukin 18 is a primary mediator of the inflammation associated with dextran sulphate sodium induced colitis: blocking interleukin 18 attenuates intestinal damage. Gut 50, 812-820. doi: 10.1136/gut.50.6.812

Sloan-Lancaster, J., Abu-Raddad, E., Polzer, J., Miller, J. W., Scherer, J. C., De Gaetano, A., et al. (2013). Double-blind, randomized study evaluating the glycemic and anti-inflammatory effects of subcutaneous LY2189102, a neutralizing IL-1beta antibody, in patients with type 2 diabetes. Diabetes Care 36, 2239-2246. doi: $10.2337 / \mathrm{dc} 12-1835$

Sonnichsen, A., Saulite, I., Mangana, J., Kerl, K., Mehra, T., Desislava, I., et al. (2016). Interleukin-1 receptor antagonist (anakinra) for Schnitzler syndrome. J. Dermatolog. Treat. 27, 436-438. doi: 10.3109/09546634.2015.1136048

Stack, J. H., Beaumont, K., Larsen, P. D., Straley, K. S., Henkel, G. W., Randle, J. C., et al. (2005). IL-converting enzyme/caspase-1 inhibitor VX-765 blocks the hypersensitive response to an inflammatory stimulus in monocytes from familial cold autoinflammatory syndrome patients. J. Immunol. 175, 2630-2634. doi: 10.4049/jimmunol.175.4.2630

Symons, J. A., Young, P. R., and Duff, G. W. (1995). Soluble type II interleukin 1 (IL-1) receptor binds and blocks processing of IL-1 beta precursor and loses affinity for IL-1 receptor antagonist. Proc. Natl. Acad. Sci. U.S.A. 92, 1714-1718. doi: $10.1073 /$ pnas.92.5.1714 
Takei, S., Hoshino, T., Matsunaga, K., Sakazaki, Y., Sawada, M., Oda, H., et al. (2011). Soluble interleukin-18 receptor complex is a novel biomarker in rheumatoid arthritis. Arthritis Res. Ther. 13, R52. doi: 10.1186/ar3295

Ter Haar, N. M., Jeyaratnam, J., Lachmann, H. J., Simon, A., Brogan, P. A., Doglio, M., et al. (2016). The phenotype and genotype of mevalonate kinase deficiency: a series of 114 cases from the eurofever registry. Arthritis Rheumatol. 68, 2795-2805. doi: 10.1002/art.39763

Timper, K., Seelig, E., Tsakiris, D. A., and Donath, M. Y. (2015). Safety, pharmacokinetics, and preliminary efficacy of a specific anti-IL-1alpha therapeutic antibody (MABp1) in patients with type 2 diabetes mellitus. J. Diabetes Complications 29, 955-960. doi: 10.1016/j.jdiacomp.2015.05.019

Tsitsami, E., Papadopoulou, C., and Speletas, M. (2013). A case of hyperimmunoglobulinemia d syndrome successfully treated with canakinumab. Case Rep. Rheumatol. 2013:795027. doi: 10.1155/2013/795027

Tzanetakou, V., Kanni, T., Giatrakou, S., Katoulis, A., Papadavid, E., Netea, M. G., et al. (2016). Safety and efficacy of anakinra in severe hidradenitis suppurativa: a randomized clinical trial. JAMA Dermatol. 152, 52-59. doi: 10.1001/jamadermatol.2015.3903

Ulusoy, E., Karaca, N. E., El-Shanti, H., Kilicoglu, E., Aksu, G., and Kutukculer, N. (2015). Interleukin-1 receptor antagonist deficiency with a novel mutation; late onset and successful treatment with canakinumab: a case report. J. Med. Case Rep. 9, 145. doi: 10.1186/s13256-015-0618-4

Ushio, S., Namba, M., Okura, T., Hattori, K., Nukada, Y., Akita, K., et al. (1996). Cloning of the cDNA for human IFN-gamma-inducing factor, expression in Escherichia coli, and studies on the biologic activities of the protein. J. Immunol. 156, 4274-4279.

van der Burgh, R., Ter Haar, N. M., Boes, M. L., and Frenkel, J. (2013). Mevalonate kinase deficiency, a metabolic autoinflammatory disease. Clin. Immunol. 147, 197-206. doi: 10.1016/j.clim.2012.09.011

van der Meer, J. W., Vossen, J. M., Radl, J., van Nieuwkoop, J. A., Meyer, C. J., Lobatto, S., et al. (1984). Hyperimmunoglobulinaemia D and periodic fever: a new syndrome. Lancet 1, 1087-1090. doi: 10.1016/S0140-6736(84)92505-4

van der Zee, H. H., de Ruiter, L., van den Broecke, D. G., Dik, W. A., Laman, J. D., and Prens, E. P. (2011). Elevated levels of tumour necrosis factor (TNF)-alpha, interleukin (IL)-1beta and IL-10 in hidradenitis suppurativa skin: a rationale for targeting TNF-alpha and IL-1beta. Br. J. Dermatol. 164, 1292-1298. doi: $10.1111 /$ j.1365-2133.2011.10254.x

van der Zee, H. H., and Prens, E. P. (2013). Failure of anti-interleukin-1 therapy in severe hidradenitis suppurativa: a case report. Dermatology 226, 97-100. doi: 10.1159/000343221

Vanderschueren, S., and Knockaert, D. (2013). Canakinumab in Schnitzler syndrome. Semin. Arthritis Rheum. 42, 413-416. doi: 10.1016/j.semarthrit.2012. 06.003

Vertex. (2007). Vertex Form 10-K Annual Report. Available at: http://investors.vrtx. com/secfiling.cfm?filingID $=1104659-07-15545 \& \mathrm{CIK}=875320$

Vertex. (2011). Vertex Form 10-K Annual Report. Available at: http://investors.vrtx. com/secfiling.cfm?filingID=1047469-11-1025

Viguier, M., Guigue, P., Pages, C., Smahi, A., and Bachelez, H. (2010). Successful treatment of generalized pustular psoriasis with the interleukin-1-receptor antagonist Anakinra: lack of correlation with IL1RN mutations. Ann. Intern. Med. 153, 66-67. doi: 10.7326/0003-4819-153-1-201007060-00030

Vitale, A., Rigante, D., Caso, F., Brizi, M. G., Galeazzi, M., Costa, L., et al. (2014). Inhibition of interleukin-1 by canakinumab as a successful mono-drug strategy for the treatment of refractory Behcet's disease: a case series. Dermatology 228, 211-214. doi: 10.1159/000358125

Wannamaker, W., Davies, R., Namchuk, M., Pollard, J., Ford, P., Ku, G., et al. (2007). (S)-1-((S)-2-\{[1-(4-amino-3-chloro-phenyl)-methanoyl]-amino $\}$ 3,3-dimethyl-butanoy 1)-pyrrolidine-2-carboxylic acid ((2R,3S)-2-ethoxy-5oxo-tetrahydro-furan-3-yl)-amide (VX-765), an orally available selective interleukin (IL)-converting enzyme/caspase-1 inhibitor, exhibits potent antiinflammatory activities by inhibiting the release of IL-1beta and IL-18. J. Pharmacol. Exp. Ther. 321, 509-516. doi: 10.1124/jpet.106.111344
Weber, A., Wasiliew, P., and Kracht, M. (2010). Interleukin-1 (IL-1) pathway. Sci. Signal. 3:cm1. doi: 10.1126/scisignal.3105 $\mathrm{cm} 1$

Wendling, D., Prati, C., and Aubin, F. (2012). Anakinra treatment of SAPHO syndrome: short-term results of an open study. Ann. Rheum. Dis. 71, 1098-1100. doi: 10.1136/annrheumdis-2011-200743

Werman, A., Werman-Venkert, R., White, R., Lee, J. K., Werman, B., Krelin, Y., et al. (2004). The precursor form of IL-1alpha is an intracrine proinflammatory activator of transcription. Proc. Natl. Acad. Sci. U.S.A. 101, 2434-2439. doi: 10.1073/pnas.0308705101

Wilson, K. P., Black, J. A., Thomson, J. A., Kim, E. E., Griffith, J. P., Navia, M. A., et al. (1994). Structure and mechanism of interleukin-1 beta converting enzyme. Nature 370, 270-275. doi: 10.1038/370270a0

Wise, C. A., Gillum, J. D., Seidman, C. E., Lindor, N. M., Veile, R., Bashiardes, S., et al. (2002). Mutations in CD2BP1 disrupt binding to PTP PEST and are responsible for PAPA syndrome, an autoinflammatory disorder. Hum. Mol. Genet. 11, 961-969. doi: 10.1093/hmg/11.8.961

Xbiotech (2017). XBiotech Meets Primary Endpoint in Phase 2 Study of MABp1 for Treatment of Hidradenitis Suppurativa (HS). Available at: http://investors.xbiotech.com/phoenix.zhtml?c=253990\&p=irol-newsArticle\& $\mathrm{ID}=2246777$

Xoma (2013). XOMA Announces Encouraging Interim Results From Gevokizumab Phase 2 Study for Moderate to Severe Acne Vulgaris. Available at: http:// investors.xoma.com/releasedetail.cfm?ReleaseID $=731711$

Xoma (2015). XOMA Announces Results From Phase 3 EYEGUARD(TM)-B Study. Available at: http://investors.xoma.com/releasedetail.cfm?releaseid=923200

Xoma (2016). XOMA Reports Fourth Quarter and Full-Year 2015 Financial Results. Available at: http://investors.xoma.com/releasedetail.cfm?releaseid=959741

Yokota, S., Imagawa, T., Nishikomori, R., Takada, H., Abrams, K., Lheritier, K., et al. (2016). Long-term safety and efficacy of canakinumab in cryopyrinassociated periodic syndrome: results from an open-label, phase III pivotal study in Japanese patients. Clin. Exp. Rheumatol. (in press).

Youm, Y. H., Nguyen, K. Y., Grant, R. W., Goldberg, E. L., Bodogai, M., Kim, D., et al. (2015). The ketone metabolite beta-hydroxybutyrate blocks NLRP3 inflammasome-mediated inflammatory disease. Nat. Med. 21, 263-269. doi: $10.1038 / \mathrm{nm} .3804$

Zarchi, K., Dufour, D. N., and Jemec, G. B. (2013). Successful treatment of severe hidradenitis suppurativa with anakinra. JAMA Dermatol. 149, 1192-1194. doi: 10.1001/jamadermatol.2013.5377

Zelensky, A. N., and Gready, J. E. (2005). The C-type lectin-like domain superfamily. FEBS J. 272, 6179-6217. doi: 10.1111/j.1742-4658.2005. 05031.x

Zhong, F. L., Mamai, O., Sborgi, L., Boussofara, L., Hopkins, R., Robinson, K., et al. (2016). Germline NLRP1 mutations cause skin inflammatory and cancer susceptibility syndromes via inflammasome activation. Cell 167, 187-202.e17. doi: 10.1016/j.cell.2016.09.001

Zhou, R., Yazdi, A. S., Menu, P., and Tschopp, J. (2011). A role for mitochondria in NLRP3 inflammasome activation. Nature 469, 221-225. doi: 10.1038/ nature09663

Zykova, T. A., Zhu, F., Zhai, X., Ma, W. Y., Ermakova, S. P., Lee, K. W., et al. (2008). Resveratrol directly targets COX-2 to inhibit carcinogenesis. Mol. Carcinog. 47, 797-805. doi: 10.1002/mc.20437

Conflict of Interest Statement: The authors declare that the research was conducted in the absence of any commercial or financial relationships that could be construed as a potential conflict of interest.

Copyright (C) 2017 Fenini, Contassot and French. This is an open-access article distributed under the terms of the Creative Commons Attribution License (CC BY). The use, distribution or reproduction in other forums is permitted, provided the original author(s) or licensor are credited and that the original publication in this journal is cited, in accordance with accepted academic practice. No use, distribution or reproduction is permitted which does not comply with these terms. 